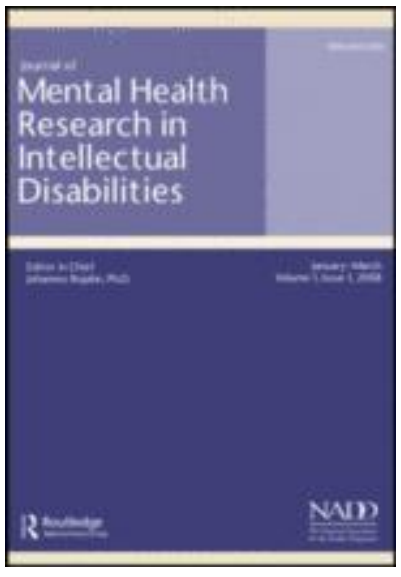

\title{
Ascertainment and prevalence of post traumatic stress disorder (PTSD) in people with intellectual disabilities
}

\begin{tabular}{|r|l|}
\hline Journal: & Journal of Mental Health Research in Intellectual Disabilities \\
\hline Manuscript ID & UMID-2018-0016.R4 \\
\hline Manuscript Type: & Original Paper \\
\hline Keywords: & mental health, learning disabilities, PTSD, Screening, Prevalence \\
\hline \multicolumn{2}{|l}{} \\
\end{tabular}

\section{SCHOLARONE \\ Manuscripts}




\title{
Ascertainment and prevalence of post traumatic stress disorder
}

\section{(PTSD) in people with intellectual disabilities}

\author{
Abstract \\ Introduction: Post-traumatic stress disorder (PTSD) may be under-recognized in people with \\ intellectual disabilities (PWID) and reviews on appropriate screening tools and prevalence are \\ lacking. This review aims to identify PTSD screening tools for PWID and estimate the \\ prevalence of PTSD within this population. Method: Medline, PubMed, Embase, PsycINFO, \\ Cochrane, Global Health and Web of Science databases were searched (inception to October \\ 2017) to identify eligible literature. Papers were also found via manual searches of the \\ references of eligible studies. Studies were reviewed in accordance with the Preferred \\ Reporting Items for Systematic reviews and Meta-analyses (PRISMA) guidelines, subjected \\ to exclusion criteria, and quality appraised using STROBE criteria for observational studies \\ and an adapted form of the Newcastle-Ottawa scale for cross-sectional studies. Seven studies \\ were identified. Meta-analysis was carried out on the prevalence studies and heterogeneity \\ quantified using $\mathrm{I}^{2}$. Results: Three tools for screening PTSD in PWID were found: two for use \\ in adults (the Lancaster and Northgate Trauma Scale and the Impact of Event Scale - \\ Intellectual Disabilities) and the Adapted Anxiety Disorders Interview Schedule for Children \\ with PTSD. Five studies reported PTSD prevalence in PWID. The weighted pooled \\ prevalence of PTSD in PWID was found to be $10 \%, 95 \%$ CI $[0.4 \%, 19.5 \%]$, towards the \\ upper limit of estimated PTSD prevalence in the general population (5-10\%). Conclusion: \\ PTSD can be diagnosed in PWID but may go unrecognized by healthcare professionals. The \\ identified tools should be further compared and assessed for acceptability and efficacy to \\ improve the identification of PTSD in PWID. \\ Keywords: mental health, learning disabilities, PTSD, screening, prevalence
}




\section{Introduction}

Post-traumatic stress disorder (PTSD) is a mental disorder that can develop as a result of an exceptionally threatening or catastrophic event (National Institute for Health and Care Excellence, 2005). Such events include assault, road traffic accidents, sexual abuse and domestic violence (Balogh et al., 2001; National Institute for Health and Care Excellence, 2005). The Diagnostic and Statistical Manual of Mental Disorders, 5th Edition (DSM-5) diagnosis criteria include re-experiencing symptoms such as flashbacks and nightmares as well as avoidance behavior, hyperarousal and negative changes in cognitions and mood (American Psychiatric Association, 2013a). Such symptoms must last for longer than one month (American Psychiatric Association, 2013a) and typically begin within six months of the trauma (Streeruwitz, Hagger, Webb, Walker, \& Jakeman, 2009). Risk factors include neurotic personality traits, a lack of social support, a history of psychiatric problems, substance misuse and childhood abuse; twin studies also reveal genetic susceptibility (Streeruwitz et al., 2009). It is important to appreciate that people with intellectual disabilities (PWID) can also experience trauma and go on to develop PTSD (Fletcher et al., 2016). An intellectual disability is defined as a "developmental condition characterized by global impairment of intelligence and significant difficulties in socially adaptive functioning" (Cader \& Paschos, 2009, p. 202) with onset before the age of 18 (American Psychiatric Association, 2013b; Mevissen et al., 2016). Intellectual disabilities are divided into "mild" (IQ 50-69), "moderate" (IQ 35-49), "severe" (IQ 20-34) and "profound" (IQ below 20) (National Institute for Health and Care Excellence, 2014).

\section{Challenges with screening for PTSD in PWID}

Screening for PTSD in PWID presents unique challenges against a background where individuals are dealing with disability itself, issues of dependency and being part of a society that may not view them as normal (Hollins \& Sinason, 2000; Mevissen \& de Jongh, 2010; 
National Institute for Health and Care Excellence, 2015; National Institute for Health and Care Excellence, 2016). Screening is further complicated due to the considerable comorbidity of PTSD with anxiety, depression and pathological grief (McCarthy, 2001; Ryan, 1994). The unique challenges with respect to diagnosing PTSD in PWID include communication, symptom presentation and diagnostic overshadowing.

\section{Communication.}

When screening for PTSD, clinicians rely on the individual's description of their experiences and response to questions (Mevissen \& de Jongh, 2010). PWID can have receptive and expressive language limitations with reduced decision-making and cognitive capacities (Fletcher et al., 2016; Mitchell \& Doyle, 2003). Thus, the usual signs and symptoms of PTSD may not be reported or observable (National Institute for Health and Care Excellence, 2014). Additionally, PWID may try to provide answers that they deem acceptable to the clinician, so called acquiescence bias (Fletcher et al., 2016). The nature of an intellectual disability and developmental levels can also differ remarkably, leading to a wide range of communication ability and clinicians are challenged to respond to the person's individual communication style.

\section{Symptom presentation.}

The treatment setting (primary care, secondary care, community, home) and any physical health problems such as sensory impairments, can lead to differences in how mental health problems are presented (McCarthy, 2001; National Institute for Health and Care Excellence, 2014; Wigham \& Emerson, 2016).

\section{Diagnostic overshadowing.}

Diagnostic overshadowing can be defined as once clinicians have made a diagnosis of a major condition, there is a "tendency to attribute all other problems to that diagnosis, thereby leaving other co-existing conditions undiagnosed" (Neurotrauma Law Nexus, n.d.). In the 
case of PTSD in PWID, clinicians may attribute PTSD symptoms to the intellectual disability itself, for instance labeling symptoms as challenging behavior or anger (Cader \& Paschos, 2009; McCarthy, 2001; Mevissen \& de Jongh, 2010; Mevissen et al., 2016; Mitchell \& Doyle, 2003). Emotional numbing may be attributed to depression or anxiety, and flashbacks, another common symptom of PTSD, may be mistaken by the clinician as hallucinations and therefore lead to inaccurate diagnoses (Esralew, 2006).

\section{Additional factors to consider when diagnosing PTSD in PWID.}

It is widely documented that PWID are more likely to experience trauma, neglect and abuse and develop PTSD compared to the general population (Fletcher et al., 2016; Hollins \& Sinason, 2000; McCarthy, 2001; Mevissen \& de Jongh, 2010; Mevissen et al., 2016; Mitchell \& Doyle, 2003; National Institute for Health and Care Excellence, 2015; Ryan, 1994;

Wigham \& Emerson, 2016; Wigham et al., 2014). Institutional carer abuse scandals including those at Winterbourne View (Department of Health, 2012; Oakes, 2012), in the New York State developmental disability system (Halladay \& Harrington, 2015) and at Muckamore Abbey Hospital in Northern Ireland (Belfast Health and Social Care Trust, 2018) highlight the higher risk of abuse PWID can face and the importance of screening for PTSD in clinical consultations. Such abuse has included staff assaulting patients, inappropriate restraint and sexual abuse. Lower levels of intelligence are associated with a reduced ability to avoid exposure to trauma and to also cope with any PTSD effects (Mevissen \& de Jongh, 2010). Furthermore, PWID may have been subject to loss events over time such as bereavement, moving home and reduced family support and cognitive limitations or social adversity may have compromised their ability to manage stress effectively (Mevissen et al., 2016; Wigham et al., 2014).

\section{Previous research on PTSD prevalence in PWID}


Estimates of PTSD prevalence in the general population range from 5\% to $10 \%$ (Kessler, Chiu, Demler, \& Walters, 2005; Shalev, Liberzon, \& Marmar, 2017; Streeruwitz et al., 2009). Studies estimating PTSD prevalence in PWID have typically used existing measures of PTSD and tried to apply these to PWID (Mevissen \& de Jongh, 2010; Mevissen et al., 2016; Wigham et al., 2011). This approach is not ideal as such measures can involve long and complicated questionnaires as well as detailed Structured Clinical Interviews, which are not suitable for PWID, according to their intellectual ability. As such, there is a lack of research on psychometrically validated PTSD screening tools specific to the ID population (Mevissen \& de Jongh, 2010; Mevissen et al., 2016; Wigham et al., 2011). As a result of the lack of screening tools, there is little information about prevalence rates (Mevissen $\&$ de Jongh, 2010) with the risk that PTSD is under-recognized in PWID (Mitchell et al., 2006). Undiagnosed and untreated PTSD can lead to a reduced quality of life, impaired emotional, social and physical development as well as higher costs of care in the long-run (Mevissen et al., 2016). The National Institute for Health and Care Excellence (NICE) acknowledges that "mental health problems are often overlooked and therefore untreated in people with learning disabilities" (National Institute for Health and Care Excellence, 2016, p. 33). Although general guidance on the assessment and management of mental health problems in PWID is provided, specific guidance on PTSD screening is lacking (National Institute for Health and Care Excellence, 2016).

\author{
Aims of the review \\ The current review seeks to provide an update to the literature, following a 2010 \\ systematic review carried out by Mevissen and de Jongh (2010) which did not find any \\ diagnostic tools specific for PTSD in PWID, aside from DSM-4 PTSD criteria adapted for \\ PWID (DM-ID, Diagnostic Manual - Intellectual Disability). Furthermore, the review found \\ only three studies examining the prevalence of PTSD in PWID. Prevalence estimates varied
}


widely - from 2.5\% to 60\% (Firth et al., 2001; Mitchell et al., 2006; Ryan, 1994). However none of the studies identified in the review used ID-specific screening tools or tools validated for use in PWID and a pooled prevalence estimate was not provided (Mevissen \& de Jongh, 2010). This systematic review therefore has two aims:

1) Identification of screening tools for the detection of PTSD symptoms in PWID.

2) Estimation of the prevalence of PTSD in PWID.

\section{Method}

\section{Literature search strategy}

Computerized searches of the Medline, Embase, PsycINFO and Global Health databases were conducted by the first author from inception of each database to 29th October 2017 using the Ovid SP interface. The PubMed, Cochrane and Web of Science databases were searched separately. The pre-defined search terms together with the Boolean operators $O R$ and $A N D$ entered into the Title field for the two searches are detailed below.

\section{Search 1.}

"PTSD" OR "post-traumatic stress disorder" OR "post traumatic stress disorder" OR trauma OR abuse OR "life events" OR "environmental stressors" OR "stress disorder", AND

\section{Search 2.}

"learning disabilit*" OR "intellectual disabilit*" OR "developmental disabilit*" OR "learning difficult*" OR "intellectual difficult*" OR "developmental difficult*" OR "learning impair*" OR "intellectual impair*" OR "developmental impair*" OR "mental retardation" OR "mental handicap"

Learning disabilities was included as a search term in Search 2 to include studies concerning PWID who may have been incorrectly noted as having a learning disability. The terms learning disability and intellectual disability are not interchangeable and can be 
confused reflecting a changing international context (Cluley, 2017). Thus by including learning disabilities in the search terms, it is possible to carry out a more complete search and capture studies that may have included PWID that were incorrectly identified as having a learning disability. This approach would also include studies comprising both PWID and those with learning disabilities and is in line with the previous systematic review by Mevissen and de Jongh (2010) where this search term was included. Searches of English-language publications only were carried out, enhanced by examination of the references of the included studies and duplicates were removed. The search was replicated by the fourth author with the same results.

The inclusion criteria were: i) peer-reviewed journal articles in English; ii) people with intellectual disabilities, clinically verified according to DSM criteria; iii) observational study design; iv) PTSD defined via DSM diagnostic criteria, a research diagnostic tool or a validated screening tool; and v) either narrative studies on PTSD screening tools specific to PWID or studies examining PTSD prevalence within the ID population (prevalence levels reported as the number of participants meeting criteria for PTSD or a percentage from which the number of participants meeting this criteria could be calculated). Articles were excluded if they: i) related to PTSD treatment or prevention; ii) examined substance abuse amongst PWID; iii) were systematic or qualitative reviews; iv) were conference or meeting abstracts without corresponding full-length journal articles; and v) were "grey" literature (rather than being published in peer-reviewed scientific journals). For the meta-analysis, studies with fewer than 10 participants were excluded both due to the low quality nature of many case reports and because studies with such small sample sizes may distort the overall findings by over-estimating effect sizes (Levine, Asada, \& Carpenter, 2009).

\section{Study selection and data extraction}


A structured spreadsheet was used by the first author to extract the following information: study title, abstract, publication year, author and country. Titles and abstracts of the results of the search were reviewed and screened for suitability and relevance using an inclusion/exclusion process. The full text of articles that met the inclusion criteria were obtained.

\section{Quality appraisal}

STROBE (Strengthening the Reporting of Observational Studies in Epidemiology) criteria for observational studies (Vandenbroucke et al., 2007) and an adapted form of the Newcastle-Ottawa scale for cross-sectional studies (Modesti et al., 2016; Wells et al., 2009) were used by the first and fourth authors independently to evaluate the quality of the papers; any disagreements were resolved through discussion. Two tools were used to provide a more detailed quality appraisal of the studies and while both are suitable for observational studies, the Newcastle-Ottawa scale has a focus on sample selection while the STROBE statement is a detailed checklist balanced across the key sections of a study. The statement consists of a 22item checklist with each component scored, relating to the title (needs to indicate the study's design), abstract (informed and balanced summary), introduction (clear rationale and specific objectives), methods (study design and setting described, participants with clear eligibility criteria, bias examined, appropriate study size and statistical methods), results (descriptive data regarding the study participants, main results and analysis carried out), discussion (clear summary of key results, limitations discussed and generalizability of findings) and source of funding provided (Vandenbroucke et al., 2007). The Newcastle-Ottawa scale, a collaboration between the Universities of Newcastle, Australia and Ottawa, Canada uses a "star system" in which a study is scored out of a maximum of 10 on three areas: 1) the selection of study groups (satisfactory sample size and representativeness, adequate response rate), 2) study design and analysis and 3) ascertainment of the outcome of interest (outcome assessment, 
appropriate statistical analysis and clearly described) (Modesti et al., 2016; Wells et al., 2009).

\section{Statistical analysis}

Meta-analysis with $95 \%$ confidence intervals (CI) was performed to estimate the weighted pooled prevalence rates of PTSD in PWID. Weighted prevalence rates and associated CI for the prevalence rates were calculated in each study and then they were pooled using the metan command in Stata (version 11.0) (Kontopantelis \& Reeves, 2010). Heterogeneity in meta-analysis examines whether the effects found in individual studies are similar enough to be confident that the combined effect of all studies is a meaningful description of the set of studies (Higgins et al., 2003). Heterogeneity describes more variation between the studies than would be expected by chance alone and is assessed using $\mathrm{I}^{2}$ (examines the weighted sum of differences between individual study effects and the pooled effect across studies) with thresholds of $\geq 25 \%, \geq 50 \%$ and $\geq 75 \%$ indicating low, moderate and high heterogeneity, respectively (Higgins et al., 2003). All analyses were conducted using a random effects model as significant heterogeneity was expected across the studies. Sensitivity analyses explored whether prevalence estimates were influenced by the study design. Planned sensitivity analyses included: i) excluding studies that retrospectively reviewed medical records to screen for PTSD so only those studies where screening was carried out via interview were included and ii) separate analyses on studies with adult participants compared to studies of children and adolescents.

\section{Search findings and study characteristics}

Figure 1 summarizes the study selection process. The total number of citations retrieved was 972 . The titles and abstracts were screened for relevance and 28 full-text articles were assessed for eligibility. This final screening process found that 21 did not meet the eligibility criteria; a full breakdown of the reasons for exclusion are provided in Figure 1. Therefore, a 
total of seven studies met the inclusion criteria and quality appraisal, four examining prevalence rates and three describing and examining PTSD screening tools for PWID (one of which also provided prevalence figures). One of the four prevalence studies was excluded from the meta-analysis due to having less than 10 participants (Bakken et al., 2014). 


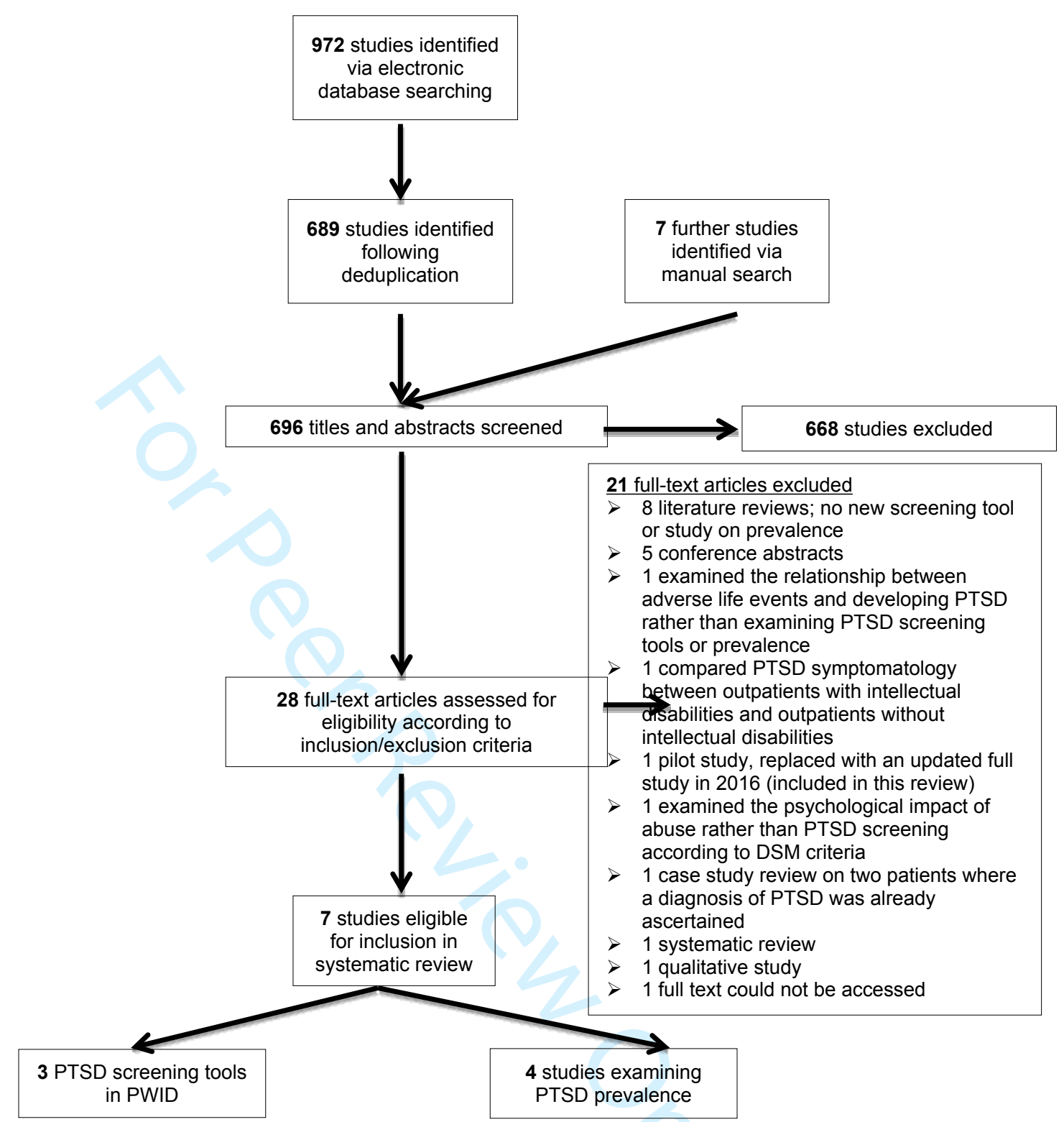

Figure 1. PRISMA flowchart of the study selection process.

\section{Descriptive characteristics of the included studies}

The three studies examining PTSD screening tools in PWID were based on a total of 219 participants (range 40-99). Two of the studies were conducted in the UK and one in the Netherlands. All studies were observational and are summarized in Table 1 (Appendix A). The study by Mevissen et al. (2016) also provided a PTSD prevalence estimate based on the 80 participants in their study. 
The four studies that examined PTSD prevalence in PWID were based on a total sum of 1,381 participants. The number of participants ranged from five to 1,023 . Two of the studies were conducted in the UK, and one each in the US and in Norway. Measures used to screen for PTSD included semi-structured interviews and a review of case notes, analyzed according to either DSM-3R, DSM-4 or DM-ID criteria. The studies are summarized in Table 2 (Appendix A).

\section{Results}

\section{Screening tools}

The three identified PTSD screening tools psychometrically appropriate for PWID are the Lancaster and Northgate Trauma Scale (LANTS) (Wigham et al., 2011), the Impact of Events Scale - Intellectual Disabilities (IES-ID) (Hall, Jobson, \& Langdon, 2014) and the Adapted Anxiety Disorders Interview Schedule for Children (ADIS-C PTSD) (Mevissen et al., 2016). Further details about the studies including the sample characteristics, results as well as strengths and limitations are provided in Appendix A.

The LANTS is a 29-item self-report (with four Likert scale response options) with a 43item informant measure of the effects of traumatic life events on PWID. The scale was developed for adults with mild to moderate ID and the informant measure provides a useful addition which can be completed by carers to provide further screening information. The key drawbacks of this tool include it being a rather long item list for both the self-report and informant measures and although the tool measures trauma-related psychopathology, it does not enable a diagnosis of PTSD based on standard diagnostic criteria. However it could be adapted to do so (S. Wigham, personal communication, November 21, 2017). The IES-ID (Hall et al., 2014) is also designed for adults with mild ID but in contrast to the LANTS, is an adapted form of the Impact of Events Scale (Weiss, 2007) and is a shorter self-report questionnaire at 22 items and provides three rather than four Likert scale response options for 
PWID to complete. There is no informant element and the tool corresponds directly with DMID diagnostic criteria of avoidance, intrusion and hyperarousal. Finally, the ADIS-C PTSD (Mevissen et al., 2016) is the first screening tool assessing PTSD specifically in children with ID. The tool accords with DM-ID 2 PTSD diagnostic criteria, has a caregiver version and could be adapted to an adult version (Mevissen-Renckens, 2017). A drawback is that the instrument lacks a version for children with more severe ID; it is recommended that the caregiver version of the ADIS-C PTSD is used for this purpose (Mevissen-Renckens, 2017).

\section{Prevalence of PTSD or PTSD symptoms in PWID}

Data from 1,453 participants in four studies contributed to the meta-analysis. The weighted pooled prevalence of PTSD in PWID was 10\%, 95\% CI [0.4\%, 19.5\%], see Figure 2. However, there were large variations across the studies in the reported rates of PTSD, ranging from $0.3 \%$ to $23.4 \%$ and heterogeneity was high $\left(\mathrm{I}^{2}=96.3 \%\right)$. Differences in the diagnostic method (interview vs. review of case notes), the age of the participants (children and adolescents vs. adults) and the treatment setting (inpatient vs. community) could drive the variation. Furthermore, different versions of the DSM PTSD criteria were used which reduces the ability to compare across the studies and adds a limitation to pooling the prevalence figures. It is also important to bear in mind that having a positive screen for PTSD symptoms does not necessarily equate to being diagnosed with PTSD according to formal diagnostic criteria (American Psychiatric Association, 2013a). Screening tools are not the same as receiving a formal diagnosis from a structured clinical interview; while the tools may pick up PTSD symptoms in an individual, these may not meet the full diagnostic criteria of PTSD (American Psychiatric Association, 2013a). Ryan (1994) used DSM-3 criteria and benefitted from a relatively large sample size of 310 , finding a prevalence of $16.5 \%$; however the sample did not include inpatients nor those with severe to profound ID. Firth et al. (2001) (child and adolescent inpatient population, $n=43)$ and Cooper et al. (2007) (1,023 outpatients) used 
DSM-4 diagnostic criteria and found prevalence rates of $2.3 \%$ and $0.3 \%$ respectively.

Mevissen et al. (2016) examined prevalence as part of investigating the psychometric properties of the PTSD screening tool, finding a prevalence of $23.3 \%$ (based on interviews with the children and adolescents) and 32.5\% (based on interviews with the caregiver).

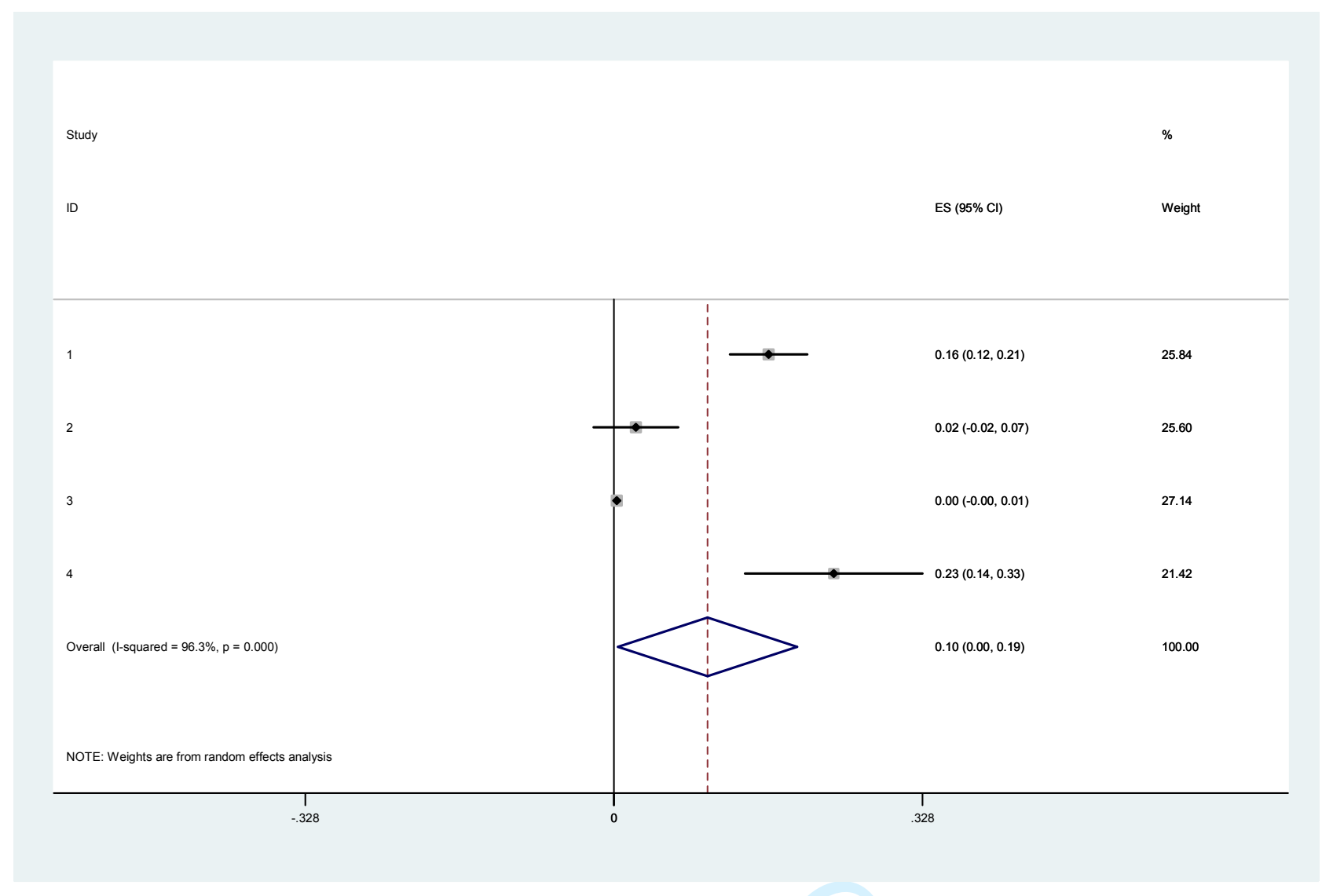

Figure 2. Forest plot of the prevalence rates of PTSD in PWID. Meta-analysis of individual study and pooled effects. Random effects model used. $95 \% \mathrm{CI}=95 \%$ confidence intervals; $\mathrm{ES}=$ Prevalence rates.

The prevalence study carried out by Bakken et al. (2014) (excluded from the meta analysis due to having less than 10 participants) comprised interviews of five PWID from a psychiatric inpatient unit in Norway and their informants according to the DM-ID (Diagnostic Manual Intellectual Disability) criteria (Fletcher et al., 2016). The six criteria, derived from DSM-TRIV, include confirmation of exposure to a traumatic event which is persistently reexperienced, avoidance of stimuli associated with the trauma, increased arousal, distress and 
impairment in functioning with symptom duration of more than 1 month. Although this study has a small sample size, and found a PTSD prevalence rate of $100 \%$, its key strength is that it screened for PTSD in individuals with moderate to severe ID.

\section{Sensitivity analysis}

Table 5 shows prevalence estimates according to each sensitivity analysis, in comparison with the primary analysis. On excluding the study by Firth et al. (2001) who carried out a retrospective review of case notes of inpatients without interviews, prevalence increased to $13 \%$ and heterogeneity to $97.5 \%$ (i.e., increased variation between the studies in this subset, more than would be expected by chance alone). The other studies carried out interviews with patients from a community setting. For the two studies with adult participants only, prevalence decreased to $8 \%$ but heterogeneity increased to $98.3 \%$ compared with the primary analysis. While for the two studies with child and adolescent participants only (Firth et al., 2001, Mevissen et al., 2016), prevalence increased to $12 \%$ and heterogeneity decreased to $93.6 \%$ compared with the primary analysis (implying reduced variation amongst the studies in this subset). Thus, the results indicate a higher prevalence of PTSD in children and adolescents with intellectual disabilities compared to adults. However, this could be the result of a measurement issue given the small number (only two studies covering each population) and low quality of the identified studies employing varied assessment tools, as one would expect PTSD at childhood and adolescence to continue into adulthood.

Table 5. Impact of study characteristics on prevalence estimates for PTSD in PWID: sensitivity analysis.

\begin{tabular}{l|l}
\hline Primary Analysis & Prevalence Results and $\mathbf{I}^{\mathbf{2}}$ \\
& $10,95 \% \mathrm{CI}[0.4,20]$ \\
& $\begin{array}{l}\mathrm{I}^{2}=96.3 \\
\text { Four studies } \\
1,453 \text { participants }\end{array}$ \\
\hline Sensitivity Analysis & $13,95 \%$ CI [-1.3, 27] \\
Excluding study that retrospectively reviewed medical records to & $\begin{array}{l}2=97.5 \\
\text { screen for PTSD, used outpatients only } \\
\text { Three studies } \\
1,410 \text { participants }\end{array}$ \\
\hline
\end{tabular}




\begin{tabular}{|c|c|}
\hline Studies with adult participants only & $\begin{array}{l}8,95 \% \text { CI }[-8,24] \\
\mathrm{I}^{2}=98.3 \\
\text { Two studies } \\
1,333 \text { participants }\end{array}$ \\
\hline Studies with child and adolescent participants only & $\begin{array}{l}12,95 \% \text { CI }[-8.2,33] \\
\mathrm{I}^{2}=93.6 \\
\text { Two studies } \\
120 \text { participants }\end{array}$ \\
\hline
\end{tabular}

Note. $95 \% \mathrm{CI}=95 \%$ confidence intervals; $\mathrm{I}^{2}$ assesses study heterogeneity with thresholds of $\geq 25 \%$, $\geq 50 \%$ and $\geq 75 \%$ indicating low, moderate and high heterogeneity, respectively (Higgins et al., 2003).

\section{Critical appraisal of the included studies}

Percentage scores under the STROBE criteria (Vandenbroucke et al., 2007) ranged from $23 \%$ to $52 \%$ (table 3, Appendix A), which helps to contextualize the present study's findings, highlights the limitations of the research found and need for further high-quality studies. The lower scored studies included Ryan (1994) (23\%), Firth et al. (2001) (27\%) and Mevissen et al. (2016) (33\%) and did not meet one or more of the following criteria: including key elements of the study design early in the paper, describing the setting, providing eligibility criteria, describing efforts to address bias or explain how the study size was arrived at, describing all statistical methods, use of a flow diagram and providing the source of funding. The higher scoring studies of Wigham et al. (2011) (39\%), Hall et al. (2014) (47\%) and Cooper et al. (2007) (52\%) did not describe the setting adequately, nor efforts to address sources of bias, how the study size was arrived at nor the characteristics of study participants and did not use a flow diagram. According to the Newcastle-Ottawa scale (Modesti et al., 2016), Cooper et al. (2007) scored 6/10 with a representative sample, good sample size, use of a validated screening tool and good outcome assessment, although lacking in comparability of outcome groups and not describing statistical tests adequately. Ryan (1994) and Firth et al. (2001) scored 5/10 due to reduced sample sizes while the remaining studies scored 3/10 due to reduced sample representativeness and the self-reporting of outcomes. The results are summarized in table 4 (Appendix A). 


\section{Discussion}

\section{Summary of the main findings}

In this review we identified several new studies that indicate there is emerging interest in PTSD and its diagnosis in PWID, providing an update to the last systematic review on PTSD prevalence and screening carried out by Mevissen and de Jongh (2010). Three screening tools were found that can aid the diagnosis of PTSD in PWID. These are the Lancaster and Northgate Trauma Scale (Wigham et al., 2011), the Impact of Event Scale Intellectual Disabilities (Hall et al., 2014) and the Adapted Anxiety Disorders Interview Schedule for Children (Mevissen et al., 2016). Studies show a wide variation in the prevalence of PSTD in PWID. We carried out a meta-analysis of prevalence, finding a weighted pooled prevalence of $10 \%$. This is towards the upper limit of PTSD prevalence in the general population, estimated at 5-10\% (Kessler et al., 2005; Shalev, Liberzon, \& Marmar, 2017; Streeruwitz et al., 2009).

\section{Implications for researchers, policy makers and clinicians}

Previous studies on screening for PTSD symptoms in PWID have largely been based on DSM criteria that have not been adapted to people with intellectual disabilities (Cooper et al. 2007; Firth et al., 2001; Mitchell et al., 2006; Ryan, 1994). Given the potential communication difficulties of PWID and diagnostic overshadowing, this approach is not ideal. Symptoms of PTSD in PWID may present as challenging behavior, for instance, aggression, disruptive behavior, self-harm, agitation, distractibility, sleep problems or depressed mood (McCarthy, 2001). Self injury and social withdrawal are also more prevalent (Bakken et al., 2014). PWID can react to trauma differently depending on the level of their intellectual disability (Mitchell et al., 2006). The three identified screening tools with their use of informant measures and Likert scales are an important step in screening for PTSD symptoms in PWID and can aid the diagnosis of PTSD. Further research should be carried out 
on these tools to examine their efficacy and consistency as well as digital version options which may assist those with more severe cognitive limitations (Callaghan et al., 2003). In addition, as with any screening tool, there is a risk of obtaining false positive and false negative results and therefore, inappropriate treatment may be offered or necessary treatment withheld. As part of refining the screening tools, they should be examined for their sensitivity and specificity.

Following a diagnosis of PTSD, effective treatment should be implemented. In the general population, Eye Movement Densitization and Reprocessing (EMDR) therapy, Cognitive Behavioural Therapy (CBT) and pharmacological therapy have been shown to be effective in PTSD treatment (National Institute for Health and Care Excellence, 2005; Streeruwitz et al., 2009; World Health Organisation, 2013). It is not yet clear whether such treatment would be effective for PWID who require it although research is ongoing (Giltaij, 2004; Mevissen et al., 2016; Tharner, 2006) and effective treatments for trauma in PWID should continue to be sought.

\section{Strengths and limitations}

This paper provides an update to the literature, calculating a pooled prevalence of PTSD in PWID and identifies three PTSD screening tools for PWID. This review was performed and reported according to PRISMA (Preferred Reporting Items for Systematic reviews and Meta-analyses) guidance (Liberati et al., 2009), which aims to ensure that systematic reviews and meta-analyses are reported clearly and accurately.

The review has some limitations. First, it is clear that in order to obtain accurate prevalence data on PTSD in PWID, it is key to have accurate PTSD screening tools. The included studies varied widely in terms of research design, participants and measures used to screen for PTSD in PWID. The studies achieved low scores on quality appraisal, which helps to contextualize the present study's findings and highlights the limitations in the research 
found. Clearly, additional and higher-quality research investigating this topic needs to be conducted. In order to achieve a higher quality, research should use validated screening tools with a large sample size (at least 10 participants) and detail should be provided regarding the study design, statistical methods and potential sources of bias, incorporating diagrams / flow charts to aid explanations where appropriate. Second, it could be argued that meta-analysis of the prevalence studies is inappropriate given the high amount of variation, more than that expected due to chance i.e., there is high heterogeneity and the data may be more suited to a narrative synthesis. However, meta-analysis has the advantage of allowing direct comparison and the assignment of weights across studies; as a result, the weighted pooled prevalence may be at least as important as the individual prevalence study estimates. The large heterogeneity was accounted for by applying random effects models in pooling the prevalence rates across the studies. Sensitivity analyses also helped to identify sources of heterogeneity. Third, searches were restricted to studies in English only which excludes studies that may have met the inclusion criteria but were written in a different language. Fourth, grey literature was also excluded as it was considered highly unlikely that high quality studies on PTSD screening and prevalence in PWID would not have been published in peer-reviewed journals. However, we cannot eliminate the possibility that by excluding grey literature, undetected selection bias has been introduced.

\section{Summary}

Clinicians, families and carers should be aware that PWID are more susceptible to experiencing traumatic events, which may lead to higher levels of PTSD compared with the general population. PWID presenting with mood disorders or challenging behavior may in fact be experiencing PTSD symptoms. Training courses, education programs and national policy can help inform healthcare professionals about how trauma can present in PWID. Annual health checks of PWID may provide an opportunity at public health level to enquire 
whether any traumatic events have occurred in the past year thus ensuring that prompt referral to appropriate services for further diagnosis and treatment is initiated (National Institute for Health and Care Excellence, 2014; National Institute for Health and Care Excellence, 2016). Screening at regular intervals using appropriate tools has been shown to be effective in the general population following major disasters (National Institute for Health and Care Excellence, 2005); PWID, who are at increased risk of experiencing trauma, should not be forgotten in such screening programs. 


\section{References}

American Psychiatric Association. (2013a). Diagnostic and statistical manual of mental disorders (5th ed.). Washington, DC: American Psychiatric Publishing.

American Psychiatric Association. (2013b). DSM-5 Intellectual Disability Fact Sheet. DSM5. Washington, DC. Retrieved from https://www.psychiatry.org/.../Practice/DSM/APA_DSM-5-Intellectual-Disability.pdf Bakken, T. L., Kildahl, A. N., Gjersøe, V., Matre, E., Kristiansen, T., Ro, A., ... Høidal, S. H. (2014). Identification of PTSD in adults with intellectual disabilities in five patients in a specialised psychiatric inpatient unit. Advances in Mental Health and Intellectual Disabilities, 8(2), 91-102. https://doi.org/10.1108/AMHID-01-2013-0002

Balogh, R., Bretherton, K., Whibley, S., Berney, T., Graham, S., Richold, P., ... Firth, H. (2001). Sexual abuse in children and adolescents with intellectual disability. Journal of Intellectual Disability Research, 45(3), 194-201. https://doi.org/10.1046/j.13652788.2001.00293.X

Belfast Health and Social Care Trust. (2018). Muckamore Abbey Statement. Retrieved December 23, 2018, from http://www.belfasttrust.hscni.net/3159.htm

Cader, S., \& Paschos, D. (2009). Learning disability. In S. Stringer, L. Church, S. Davison, \& M. Lipsedge (Eds.), Psychiatry P.R.N. (pp. 201-208). New York: Oxford University Press.

Callaghan, M. A. C. O., Murphy, G. H., \& Clare, I. C. H. (2003). Symptoms of Abuse in Adults with Severe Learning Disabilities Final Report to the Dept of Health. Retrieved from https://www.kent.ac.uk/tizard/research/documents/DoH_Abuse_report_2006.pdf Cluley, V. (2017). From "Learning disability to intellectual disability" - Perceptions of the increasing use of the term " intellectual disability" in learning disability policy, research and practice. British Journal of Learning Disabilities, (October), 24-32.

https://doi.org/10.1111/bld.12209 
Esralew, L. (2006). PTSD and related stress disorders in persons with developmental disabilities (Vol. NADD IX). Retrieved from http://thenadd.org/modal/bulletins/v9n1a3 .htm

Firth, H., Balogh, R., Berney, T., Bretherton, K., Graham, S., \& Whibley, S. (2001). Psychopathology of sexual abuse in young people with intellectual disability. Journal of Intellectual Disability Research, 45(3), 244-252. https://doi.org/10.1046/j.13652788.2001.00314.x

Fletcher, R. J., Barnhill, J., McCarthy, J., \& Strydom, A. (2016). From DSM to DM-ID. Journal of Mental Health Research in Intellectual Disabilities, 9(3), 189-204. https://doi.org/10.1080/19315864.2016.1185324

Giltaij, H. (2004). Alsof er een stofzuiger door mijn hoofd is gegaan. EMDR bij mensen met een visuele en verstandelijke beperking. [As if a vacuum cleaner went through my head. EMDR in people with visual and intellectual disabilities]. Tijdschrift Voor Kinder-\& Jeugdpsychotherapie, 3, 81-97.

Hall, J. C., Jobson, L., \& Langdon, P. E. (2014). Measuring symptoms of post-traumatic stress disorder in people with intellectual disabilities: The development and psychometric properties of the Impact of Event Scale-Intellectual Disabilities (IES-IDs). British Journal of Clinical Psychology, 53(3), 315-332. https://doi.org/10.1111/bjc. 12048

Halladay, P. M., \& Harrington, C. (2015). Scandals of abuse: Policy responses in intellectual disabilities. International Journal of Sociology and Social Policy, 35, 107-124. https://doi.org/10.1108/IJSSP-12-2013-0117

Health, D. of. (2012). Transforming care: A national response to Winterbourne View Hospital. https://doi.org/Gateway reference 18348

Higgins, J. P. T., Thompson, S. G., Deeks, J. J., \& Altman, D. G. (2003). Measuring 
inconsistency in meta-analyses. BMJ : British Medical Journal, 327(7414), 557-560. https://doi.org/10.1136/bmj.327.7414.557

Hollins, S., \& Sinason, V. (2000). Psychotherapy, learning disabilities and trauma : new perspectives. British Journal of Psychiatry, 176, 32-36. https://doi.org/10.1192/bjp.176.1.32

Kessler, R., Chiu, W., Demler, O., \& Walters, E. (2005). Prevalence, severity, and comorbidity of 12-month DSM-IV disorders in the national comorbidity survey replication. Archives of General Psychiatry, 62, 617-627.

Kontopantelis, E., \& Reeves, D. (2010). The metaan command: random effects meta-analysis. The Stata Journal, 10(3), 395-407.

Levine, T., Asada, K. J., \& Carpenter, C. (2009). Sample Sizes and Effect Sizes are Negatively Correlated in Meta- Analyses : Evidence and Implications of a Publication Bias Against NonSignificant Findings. Communication Monographs, 76(3), 286-302. https://doi.org/10.1080/03637750903074685

Liberati, A., Altman, D. G., Tetzlaff, J., Mulrow, C., Gøtzsche, P. C., Ioannidis, J. P. A., ... Moher, D. (2009). The PRISMA statement for reporting systematic reviews and metaanalyses of studies that evaluate health care interventions: Explanation and elaboration. PLoS Medicine, 6(7). https://doi.org/10.1371/journal.pmed.1000100

McCarthy, J. (2001). Post-traumatic stress disorder in people with learning disability. Advances in Psychiatric Treatment, 7(3), 163-169. https://doi.org/10.1192/apt.7.3.163

Mevissen-Renckens, E. H. M. (2017). Assessment and treatment of posttraumatic stress disorder in individuals with intellectual disabilities. (PhD thesis). Retrieved from UvADARE (Digital Academic Repository).

Mevissen, L., \& de Jongh, A. (2010). PTSD and its treatment in people with intellectual disabilities. A review of the literature. Clinical Psychology Review, 30(3), 308-316. 
https://doi.org/10.1016/j.cpr.2009.12.005

Mevissen, L., Didden, R., \& Jongh, A. De. (2016). Assessment and Treatment of PTSD in People with Intellectual Disabilities. In C. R. Martin, V. R. Preedy, \& V. B. Patel (Eds.), Comprehensive Guide to Post-Traumatic Stress Disorder. Switzerland: Springer International Publishing. https://doi.org/10.1007/978-3-319-08613-2

Mevissen, L., Didden, R., Korzilius, H., \& de Jongh, A. (2016). Assessing posttraumatic stress disorder in children with mild to borderline intellectual disabilities. European Journal of Psychotraumatology, 7. https://doi.org/10.3402/ejpt.v7.29786

Mitchell, A., Clegg, J., \& Furniss, F. (2006). Exploring the meaning of trauma with adults with intellectual disabilities. Journal of Applied Research in Intellectual Disabilities, 19(2), 131-142. https://doi.org/10.1111/j.1468-3148.2005.00235.x

Mitchell, D., \& Doyle, C. (2003). Post-traumatic stress disorder and people with learning disabilities. Journal of Learning Disabilities, 7(1), 23-33.

Modesti, P. A., Reboldi, G., Cappuccio, F. P., Agyemang, C., Remuzzi, G., \& Rapi, S. (2016). Panethnic Differences in Blood Pressure in Europe : A Systematic Review and Meta- Analysis. PLoS One, 11(1), 1-21. https://doi.org/10.1371/journal.pone.0147601

National Institute for Health and Care Excellence. (2005). Post-traumatic stress disorder : management. Retrieved from https://www.nice.org.uk/guidance/cg26

National Institute for Health and Care Excellence. (2014). Mental health problems in people with learning disabilities: prevention, assessment and management. Retrieved from https://www.nice.org.uk/guidance/GID-CGWAVE0684/documents/mental-healthproblems-in-people-with-learning-disabilities-scope-consultation-comments-table2 National Institute for Health and Care Excellence. (2015). Challenging behaviour and learning disabilities: prevention and interventions for people with learning disabilities whose behaviour challenges. Retrieved from https://www.nice.org.uk/guidance/ng11 
National Institute for Health and Care Excellence. (2016). Mental health problems in people with learning disabilities: prevention, assessment and management, (July), 1-38. Retrieved from https://www.nice.org.uk/guidance/GIDCGWAVE0684/documents/mental-health-problems-in-people-with-learning-disabilitiesscope-consultation-comments-table2

Neurotrauma Law Nexus. (n.d.). Neurotrauma Law Nexus. Retrieved April 6, 2019, from http://www.neurolaw.com/neuroglossary/

Oakes, P. (2012). Crash: what went wrong at Winterbourne View? Journal of Intellectual Disabilities : JOID, 16(3), 155-62. https://doi.org/10.1177/1744629512449095

Ryan, R. (1994). Posttraumatic stress disorder in persons with developmental disabilities. Community Mental Health Journal, 30(1), 45-54. https://doi.org/10.1007/BF02188874

Shalev, A., Liberzon, I., \& Marmar, C. (2017). Post-Traumatic Stress Disorder. New England Journal of Medicine, 376(25), 2459-2469. https://doi.org/10.1056/NEJMra1612499

Streeruwitz, A., Hagger, M., Webb, S., Walker, D., \& Jakeman, N. (2009). Anxiety, obsessions, and reactions to stress. In S. Stringer, L. Church, S. Davison, \& M. Lipsedge (Eds.), Psychiatry P.R.N (pp. 147-166). New York: Oxford University Press.

Tharner, G. (2006). Over de toepassing van EMDR bij de behandeling van mensen met een lichte verstandelijke beperking. [About the application of EMDR in the treatment of people with a mild intellectual disability]. In In Robert Didden (Ed.), In perspectief. Gedragsproblemen, psychiatrische stoornissen en lichte verstandelijke beperking. Bohn Stafleu van Loghum. (pp. 145-168).

Vandenbroucke, J. P., Von Elm, E., Altman, D. G., Gøtzsche, P. C., Mulrow, C. D., Pocock, S. J., ... Egger, M. (2007). Strengthening the Reporting of Observational Studies in Epidemiology (STROBE): Explanation and elaboration. PLoS Medicine, 4(10), 16281654. https://doi.org/10.1371/journal.pmed.0040297 
Weiss, D. (2007). The Impact of Event Scale-Revised. In J. Wilson \& T. Keane (Eds.), Assessing psychological trauma and PTSD: a practitioner's handbook (2nd ed., pp. 168-189). New York: Guilford Press. https://doi.org/10.1001/jama.2016.8474

Wells, G., Shea, B., O’Connell, D., Peterson, J., Welch, V., Losos, M., \& Tugwell, P. (2009). The Newcastle-Ottawa Scale (NOS) for assessing the quality of nonrandomised studies in meta-analyses. Retrieved from http://www.ohri.ca/programs/clinical_epidemiology/oxford.asp

Wigham, S., \& Emerson, E. (2016). Trauma and life events in adults with intellectual disability. Current Developmental Disorders Reports, 2(2), 93-99. Retrieved from https://link.springer.com/article/10.1007\%2Fs40474-015-0041-y

Wigham, S., Hatton, C., \& Taylor, J. L. (2011). The effects of traumatizing life events on people with intellectual disabilities: A systematic review. Journal of Mental Health Research in Intellectual Disabilities, 4(1), 19-39.

https://doi.org/10.1080/19315864.2010.534576

Wigham, S., Hatton, C., \& Taylor, J. L. (2011). The Lancaster and Northgate Trauma Scales (LANTS): The development and psychometric properties of a measure of trauma for people with mild to moderate intellectual disabilities. Research in Developmental Disabilities, 32(6), 2651-2659. https://doi.org/10.1016/j.ridd.2011.06.008

Wigham, S., Taylor, J. L., \& Hatton, C. (2014). A prospective study of the relationship between adverse life events and trauma in adults with mild to moderate intellectual disabilities. Journal of Intellectual Disability Research, 58(12), 1131-1140. https://doi.org/10.1111/jir.12107

World Health Organisation. (2013). Guidelines for the Management of Conditions Specifically Related to Stress. Assessment and Management of Conditions Specifically Related to Stress: mhGAP Intervention Guide Module (version 1.0). Retrieved from 
http://www.ncbi.nlm.nih.gov/pubmed/24649518 
Appendix A

Table 1. Characteristics of PTSD screening tool studies included in this review.

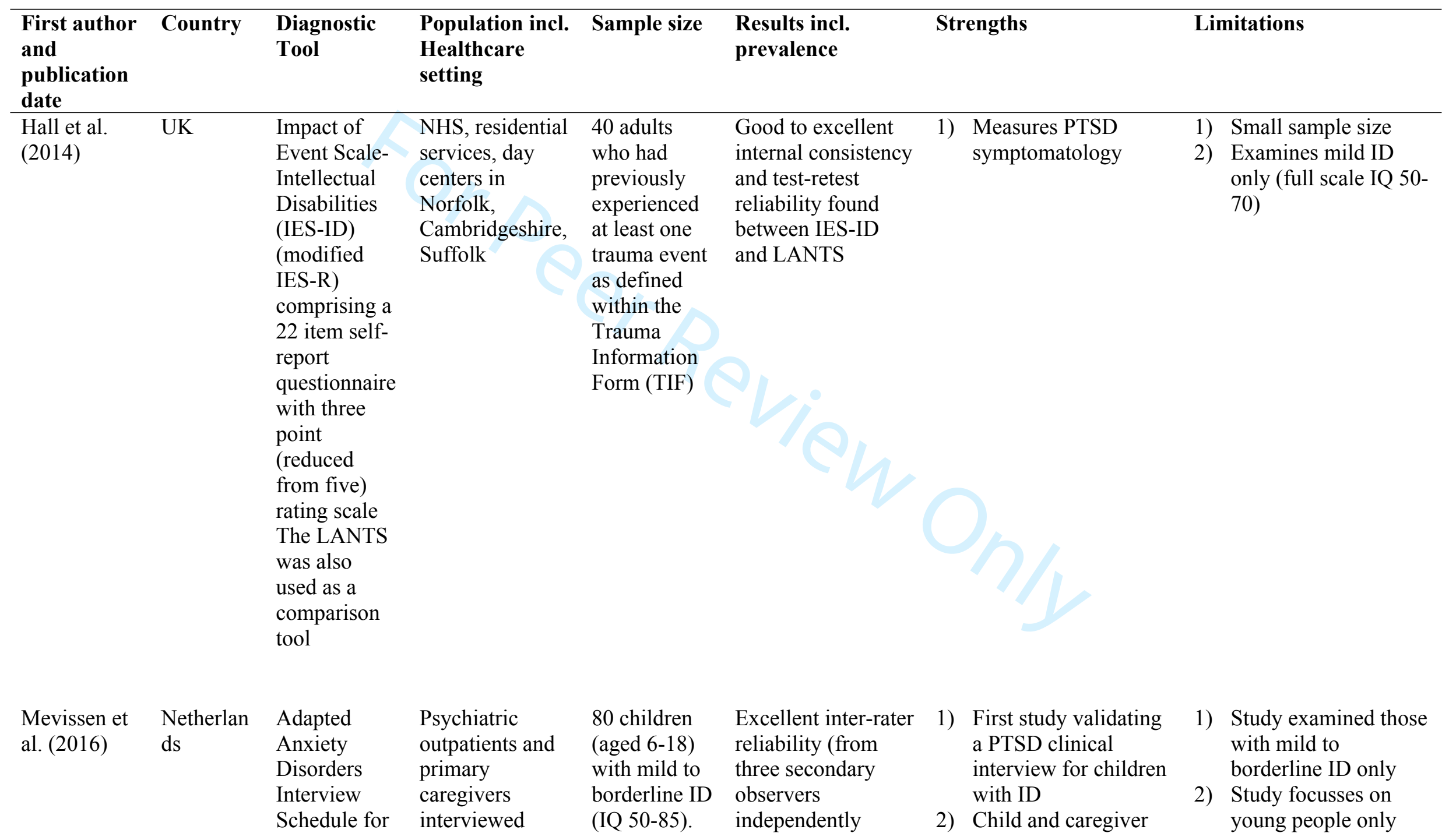




\begin{tabular}{|c|c|c|c|c|c|c|c|c|c|}
\hline & & $\begin{array}{l}\text { Children } \\
\text { (ADIS-C) } \\
\text { PTSD } \\
\text { section, } \\
\text { according to } \\
\text { DM-ID and } \\
\text { DM-ID 2 } \\
\text { criteria }\end{array}$ & & $\begin{array}{l}\text { Mean age } \\
11.6 \text { years. } \\
80 \text { primary } \\
\text { caregivers. }\end{array}$ & $\begin{array}{l}\text { scoring) and good } \\
\text { convergent validity } \\
\text { with the Child } \\
\text { Behavior Checklist } \\
\text { (CBCL) which } \\
\text { measures emotional } \\
\text { and behavioral } \\
\text { problems }\end{array}$ & & data collected & & \\
\hline & & & & & $\begin{array}{l}\text { PTSD prevalence } \\
\text { of } 23.3 \% \text { (interview } \\
\text { with child) and } \\
32.5 \% \text { (interview } \\
\text { with caregiver) } \\
\text { according to DM- } \\
\text { ID } 2 \text { criteria }\end{array}$ & & & & \\
\hline $\begin{array}{l}\text { Wigham et } \\
\text { al. (2011) }\end{array}$ & UK & $\begin{array}{l}\text { Lancaster } \\
\text { and } \\
\text { Northgate } \\
\text { Trauma } \\
\text { Scale } \\
\text { (LANTS) } \\
\text { interview } \\
\text { comprising } \\
\text { self-report } \\
\text { (29 items) } \\
\text { and } \\
\text { informant } \\
\text { measures (43 } \\
\text { items) }\end{array}$ & $\begin{array}{l}\text { NHS, day } \\
\text { center, social } \\
\text { services and } \\
\text { independent } \\
\text { service } \\
\text { providers in NE } \\
\text { England }\end{array}$ & $\begin{array}{l}99 \text { adult } \\
\text { service users } \\
(85 \text { men and } \\
14 \text { women }) \\
\text { and } 88 \text { staff }\end{array}$ & $\begin{array}{l}\text { Good validity, } \\
\text { internal consistency } \\
\text { and retest reliability }\end{array}$ & $\begin{array}{l}\text { 1) } \\
\text { 2) } \\
\text { 3) } \\
\text { 4) }\end{array}$ & $\begin{array}{l}\text { Trauma and ID } \\
\text { specific } \\
\text { Initial systematic } \\
\text { literature review as } \\
\text { well as interviews of } \\
\text { the effects of } \\
\text { traumatic life events } \\
\text { of PWID when } \\
\text { constructing the tool } \\
\text { enhanced validity } \\
\text { Carried out a pilot } \\
\text { Re-tests took place } \\
\text { five to six weeks after } \\
\text { initial interview, } \\
\text { enhancing reliability }\end{array}$ & $\begin{array}{l}\text { 1) } \\
\text { 2) }\end{array}$ & $\begin{array}{l}\text { Study examined those } \\
\text { with mild to moderate } \\
\text { ID only i.e., those } \\
\text { with severe ID were } \\
\text { not included } \\
\text { While a measure of } \\
\text { trauma-related } \\
\text { psychopathology, not } \\
\text { specific to DM-ID } 2 \\
\text { PTSD diagnostic } \\
\text { criteria }\end{array}$ \\
\hline
\end{tabular}


Table 2. Characteristics of PTSD prevalence studies included in this review.

\begin{tabular}{|c|c|c|c|c|c|c|c|c|}
\hline $\begin{array}{l}\text { First } \\
\text { author } \\
\text { and } \\
\text { publica } \\
\text { tion } \\
\text { date } \\
\end{array}$ & Country & $\begin{array}{l}\text { Diagnostic } \\
\text { Tool }\end{array}$ & $\begin{array}{l}\text { Population } \\
\text { incl. } \\
\text { Healthcare } \\
\text { setting }\end{array}$ & Sample size & $\begin{array}{l}\text { Results incl. } \\
\text { prevalence }\end{array}$ & Strengths & Li & nitations \\
\hline \multirow[t]{2}{*}{$\begin{array}{l}\text { Bakken } \\
\text { et al. } \\
(2014)\end{array}$} & Norway & $\begin{array}{l}\text { Diagnostic } \\
\text { Manual - } \\
\text { Intellectual } \\
\text { Disability } \\
\text { criteria } \\
\text { interview of } \\
\text { PWID and } \\
\text { their } \\
\text { informants }\end{array}$ & $\begin{array}{l}\text { Psychiatric } \\
\text { Inpatient } \\
\text { Unit for } \\
\text { adults with } \\
\text { ID }\end{array}$ & $\begin{array}{l}\text { Five psychiatric } \\
\text { inpatients, three } \\
\text { female and two } \\
\text { male, aged between } \\
25 \text { and } 45 . \text { Three } \\
\text { with moderate } \\
\text { intellectual } \\
\text { disabilities, one } \\
\text { moderate-severe } \\
\text { and one severe } \\
\text { intellectual } \\
\text { disabilities. }\end{array}$ & $\begin{array}{l}\mathbf{1 0 0 \%} \text { PTSD } \\
\text { prevalence } \\
\text { according to } \\
\text { DM - ID criteria }\end{array}$ & $\begin{array}{l}\text { 1) Screens for PTSD in } \\
\text { moderate to severe } \\
\text { ID }\end{array}$ & 1) & Small sample size \\
\hline & & $\begin{array}{l}\text { LANTS used } \\
\text { as a } \\
\text { comparison } \\
\text { tool for } \\
\text { patients with } \\
\text { moderate ID }\end{array}$ & & & & & & \\
\hline $\begin{array}{l}\text { Cooper } \\
\text { et al. } \\
(2007)\end{array}$ & UK & $\begin{array}{l}\text { Review of } \\
\text { case notes and } \\
\text { interview of } \\
\text { participant and } \\
\text { main carer by } \\
\text { nurse and GP. } \\
\text { Diagnosis } \\
\text { based on DM- } \\
\text { ID and ICD-10 }\end{array}$ & $\begin{array}{l}\text { Population } \\
\text { identified via } \\
\text { local social } \\
\text { work } \\
\text { services and } \\
\text { specialist } \\
\text { health } \\
\text { services }\end{array}$ & $\begin{array}{l}1,023 \text { adults }(16 \text { or } \\
\text { over) with ID, } 562 \\
(54.9 \%) \text { men and } \\
461(45.1 \%) \\
\text { women. } 38.9 \% \\
\text { mild ID, } 24.2 \% \\
\text { moderate, } 18.9 \% \\
\text { severe, } 18 \% \\
\text { profound. }\end{array}$ & $\begin{array}{l}3.8 \% \text { of the } \\
\text { cohort were } \\
\text { found to have } \\
\text { anxiety } \\
\text { disorders, of } \\
\text { which } \mathbf{0 . 3 \%} \text { had } \\
\text { a clinical } \\
\text { diagnosis of } \\
\text { PTSD (three }\end{array}$ & $\begin{array}{l}\text { 1) Large sample size } \\
\text { 2) Thorough } \\
\text { methodology and } \\
\text { approach } \\
\text { 3) Includes those with } \\
\text { severe and profound } \\
\text { ID }\end{array}$ & 1) & $\begin{array}{l}\text { Sample may not be fully } \\
\text { representative e.g. those } \\
\text { with mild ID under- } \\
\text { represented (do not } \\
\text { access any services or } \\
\text { support) }\end{array}$ \\
\hline
\end{tabular}




\begin{tabular}{|c|c|c|c|c|c|c|c|c|c|}
\hline & & $\begin{array}{l}\text { criteria. } \\
\text { Further } \\
\text { interview } \\
\text { carried out by } \\
\text { psychiatrist if } \\
\text { deemed to } \\
\text { have mental } \\
\text { health } \\
\text { condition. }\end{array}$ & & & $\begin{array}{l}\text { people of the } \\
\text { total cohort of } \\
1,023) \text {. }\end{array}$ & & & & \\
\hline $\begin{array}{l}\text { Mevisse } \\
\mathrm{n} \text { et al. } \\
(2016)\end{array}$ & $\begin{array}{l}\text { Netherland } \\
\mathrm{s}\end{array}$ & $\begin{array}{l}\text { Adapted } \\
\text { Anxiety } \\
\text { Disorders } \\
\text { Interview } \\
\text { Schedule for } \\
\text { Children } \\
\text { (ADIS-C) } \\
\text { PTSD section, } \\
\text { according to } \\
\text { DM-ID and } \\
\text { DM-ID } 2 \\
\text { criteria }\end{array}$ & $\begin{array}{l}\text { Psychiatric } \\
\text { outpatients } \\
\text { and primary } \\
\text { caregivers } \\
\text { interviewed }\end{array}$ & $\begin{array}{l}77 \text { children (aged } \\
6-18) \text { with mild to } \\
\text { borderline ID (IQ } \\
50-85 \text { ) and } \\
\text { caregivers }(\mathrm{n}=80) \\
\text { Mean age } 11.6 \\
\text { years. } 80 \text { primary } \\
\text { caregivers. }\end{array}$ & $\begin{array}{l}\text { PTSD } \\
\text { prevalence of } \\
\mathbf{2 3 . 4 \%}(18 / 77) \\
\text { was found based } \\
\text { on interviews } \\
\text { with the } \\
\text { children and } \\
\mathbf{3 2 . 5 \%}(26 / 80) \\
\text { when based on } \\
\text { interviews with } \\
\text { the caregiver. }\end{array}$ & 1) & $\begin{array}{l}\text { First study } \\
\text { validating a PTSD } \\
\text { clinical interview } \\
\text { for children with ID }\end{array}$ & $\begin{array}{l}\text { 1) } \\
\text { 2) }\end{array}$ & $\begin{array}{l}\text { Mild to borderline ID } \\
\text { only } \\
\text { Study focusses on young } \\
\text { people only }\end{array}$ \\
\hline $\begin{array}{l}\text { Ryan } \\
\text { (1994) }\end{array}$ & US & $\begin{array}{l}\text { DSM-3R } \\
\text { criteria. } \\
\text { Psychiatric } \\
\text { interview and } \\
\text { case notes } \\
\text { review. }\end{array}$ & $\begin{array}{l}\text { Referral / } \\
\text { outpatient } \\
\text { population }\end{array}$ & $\begin{array}{l}310,66 \% \text { women } \\
\text { and } 33 \% \text { men. } \\
\text { Average age } 33 . \\
\text { Moderate ID. }\end{array}$ & $\begin{array}{l}51 \text { met criteria } \\
\text { for PTSD i.e., } \\
\mathbf{1 6 . 5 \%}\end{array}$ & 1) & Large sample size & 2) & $\begin{array}{l}\text { DSM- } 3 \text { criteria used, } \\
\text { PTSD and PTSD-ID } \\
\text { criteria have been } \\
\text { updated } \\
\text { Sample drawn from } \\
\text { referral population, } \\
\text { therefore may not be } \\
\text { representative of ID }\end{array}$ \\
\hline
\end{tabular}


population. Does not

assess inpatient or severe

to profound ID

population

Note. The study by Bakken et al. (2014) was excluded from the meta-analysis due to having less than 10 participants, only the remaining 4 studies were included. 
Table 3. Critical appraisal of the included studies according to STROBE criteria (Vandenbroucke et al., 2007).

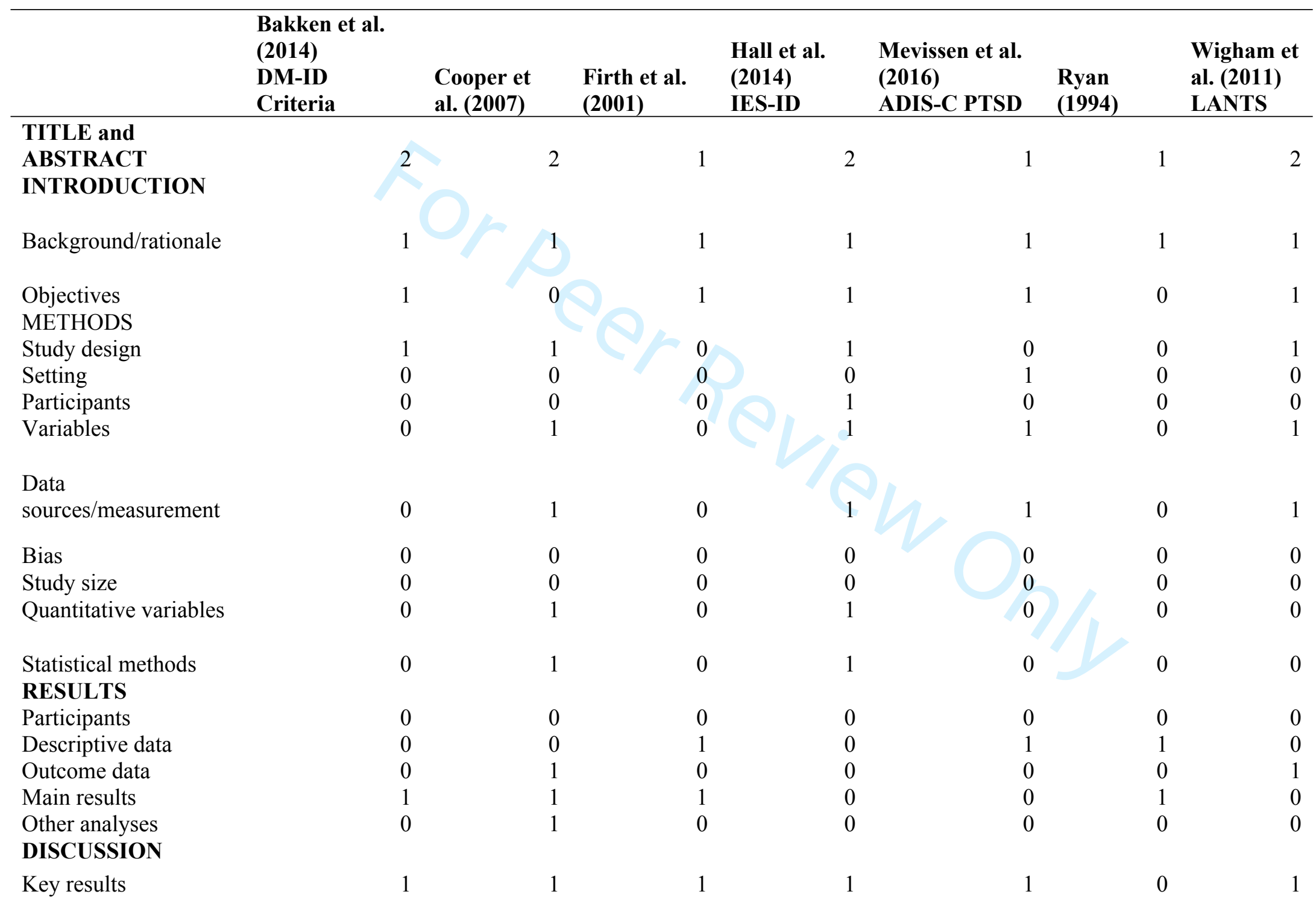




\begin{tabular}{|c|c|c|c|c|c|c|c|}
\hline Limitations & 1 & 1 & 1 & 0 & 1 & 1 & 0 \\
\hline Interpretation & 1 & 1 & 1 & 1 & 1 & 1 & 1 \\
\hline $\begin{array}{l}\text { Generalizability } \\
\text { OTHER } \\
\text { INFORMATION }\end{array}$ & 0 & 1 & 1 & 1 & 0 & 1 & 1 \\
\hline Funding & 0 & 1 & 0 & 1 & 0 & 0 & 1 \\
\hline $\begin{array}{l}\text { Total } \\
\text { Maximum possible }\end{array}$ & 9 & 16 & 9 & 14 & 10 & 7 & 12 \\
\hline $\begin{array}{l}\text { score } \\
\% \\
\end{array}$ & $\begin{array}{r}31 \\
29 \% \\
\end{array}$ & $\begin{array}{r}31 \\
52 \% \\
\end{array}$ & $\begin{array}{r}33 \\
27 \% \\
\end{array}$ & $\begin{array}{r}30 \\
47 \% \\
\end{array}$ & $\begin{array}{r}30 \\
33 \% \\
\end{array}$ & $\begin{array}{r}31 \\
23 \% \\
\end{array}$ & $\begin{array}{r}31 \\
39 \% \\
\end{array}$ \\
\hline
\end{tabular}


Table 4. Critical appraisal of the included studies according to the Newcastle-Ottawa scale (Modesti et al., 2016; Wells et al., 2009).

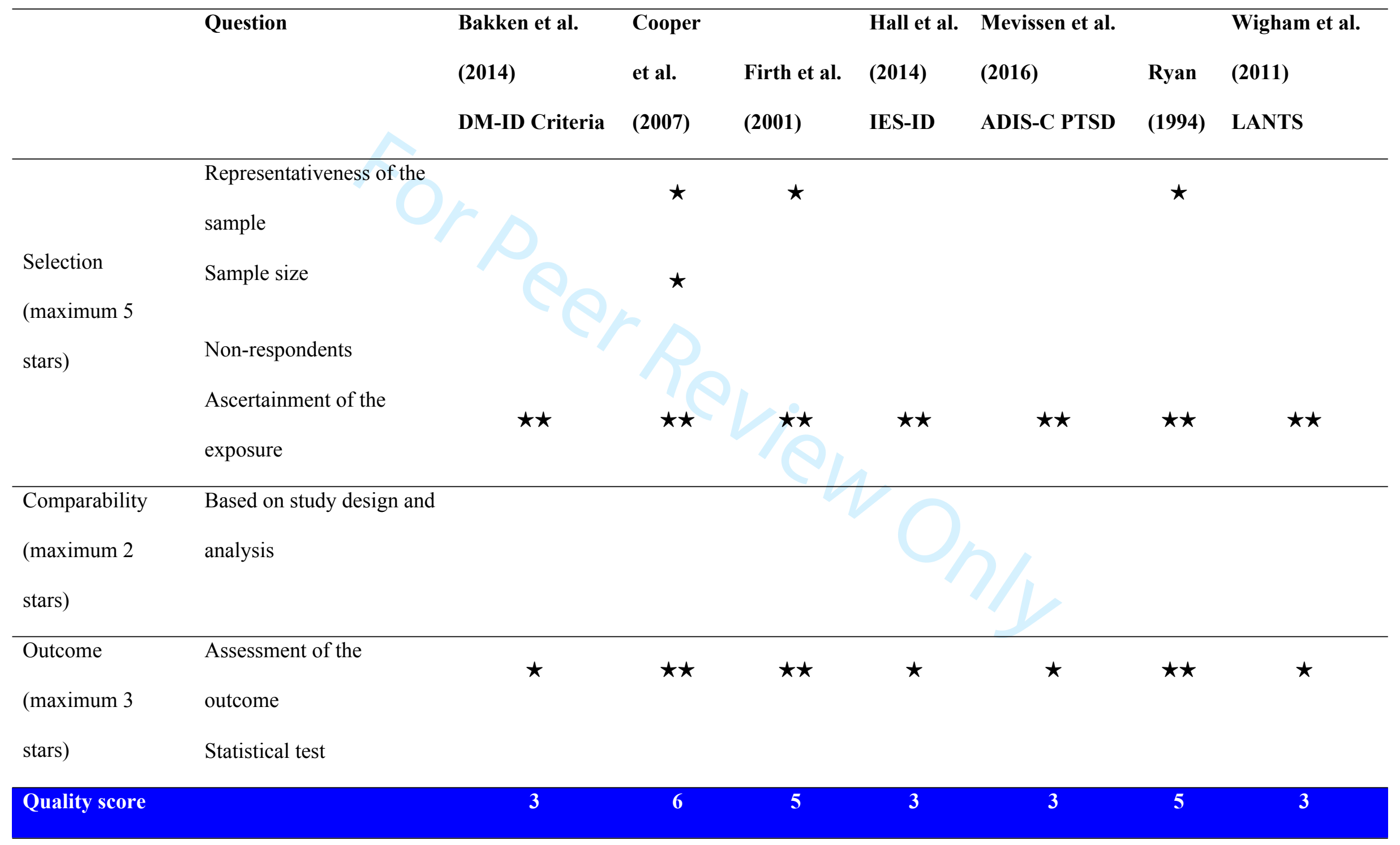


(maximum 10) 
972 studies identified via electronic database searching

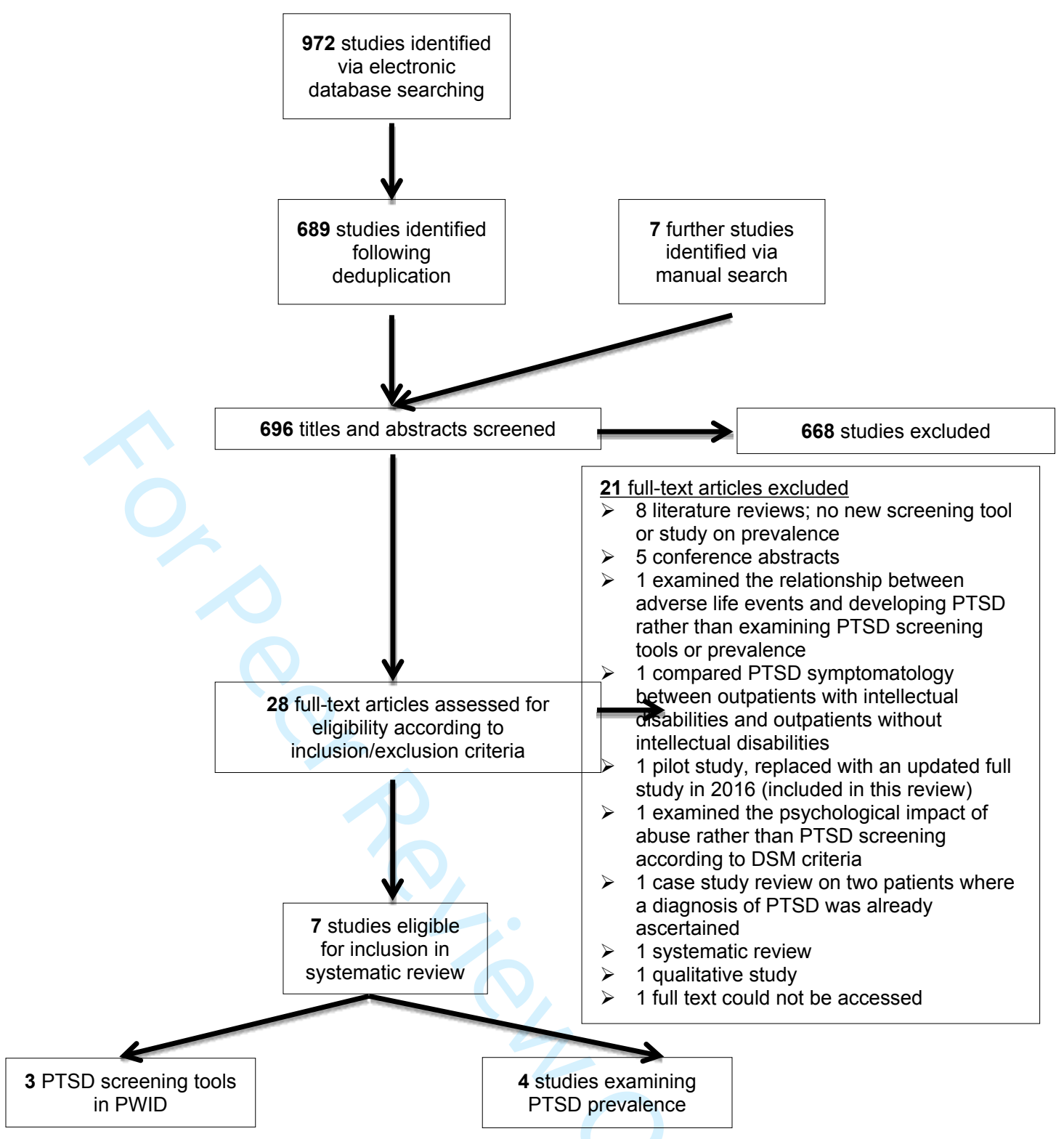

Figure 1. PRISMA flowchart of the study selection process. 


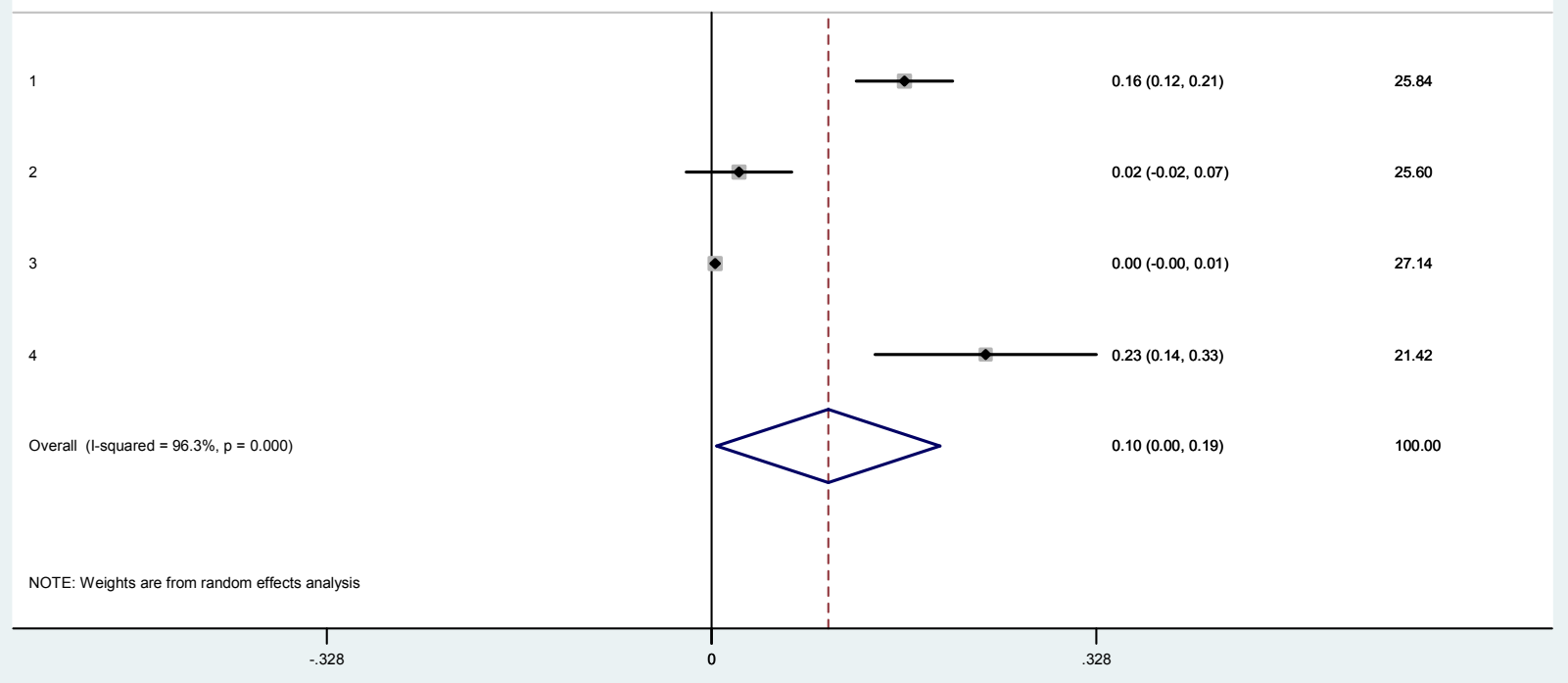

Figure 2. Forest plot of the prevalence rates of PTSD in PWID. Meta-analysis of individual study and pooled effects. Random effects model used. $95 \% \mathrm{CI}=95 \%$ confidence intervals; $\mathrm{ES}=$ Prevalence rates. 
Appendix A

Table 1. Characteristics of PTSD screening tool studies included in this review.

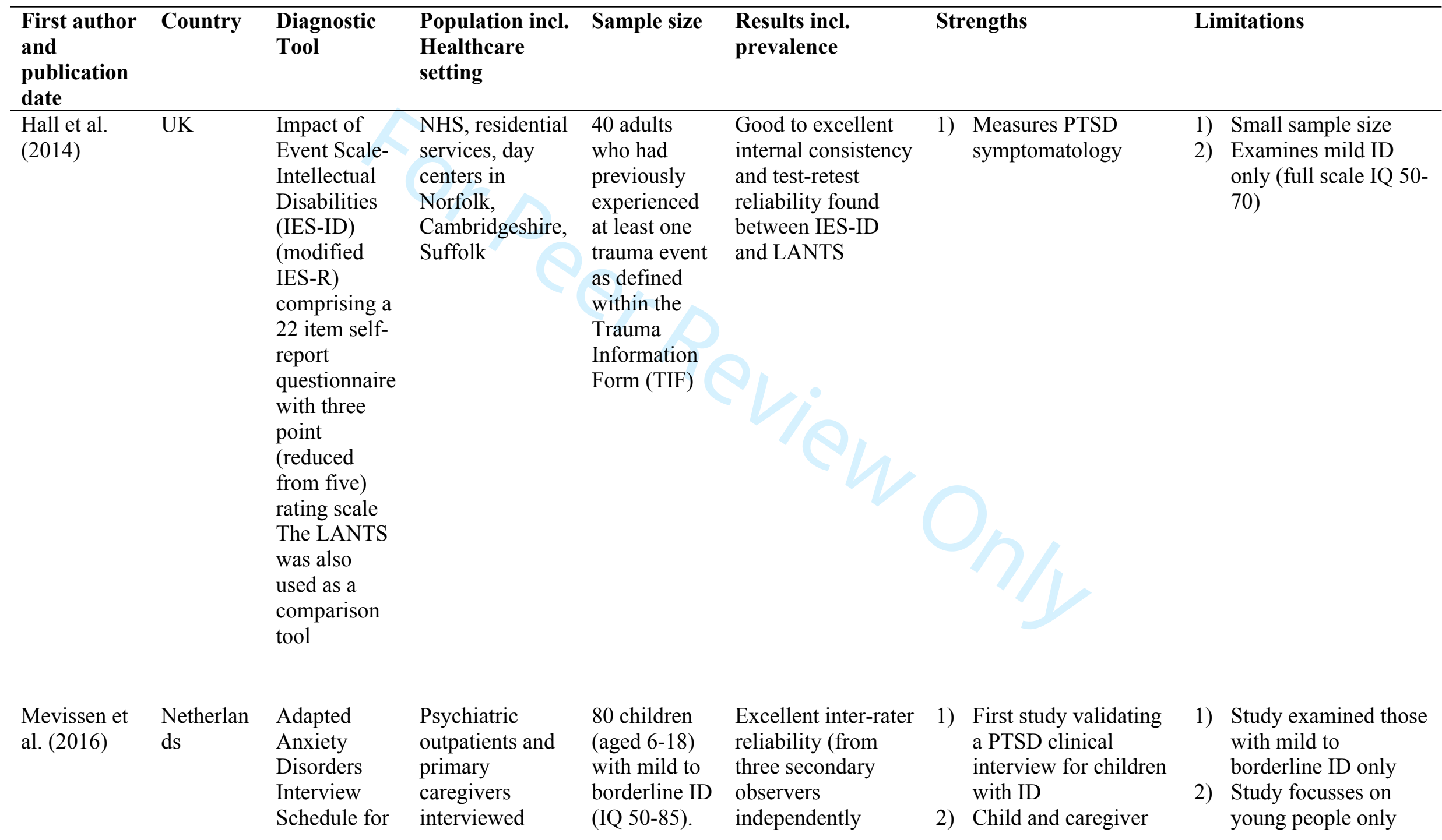




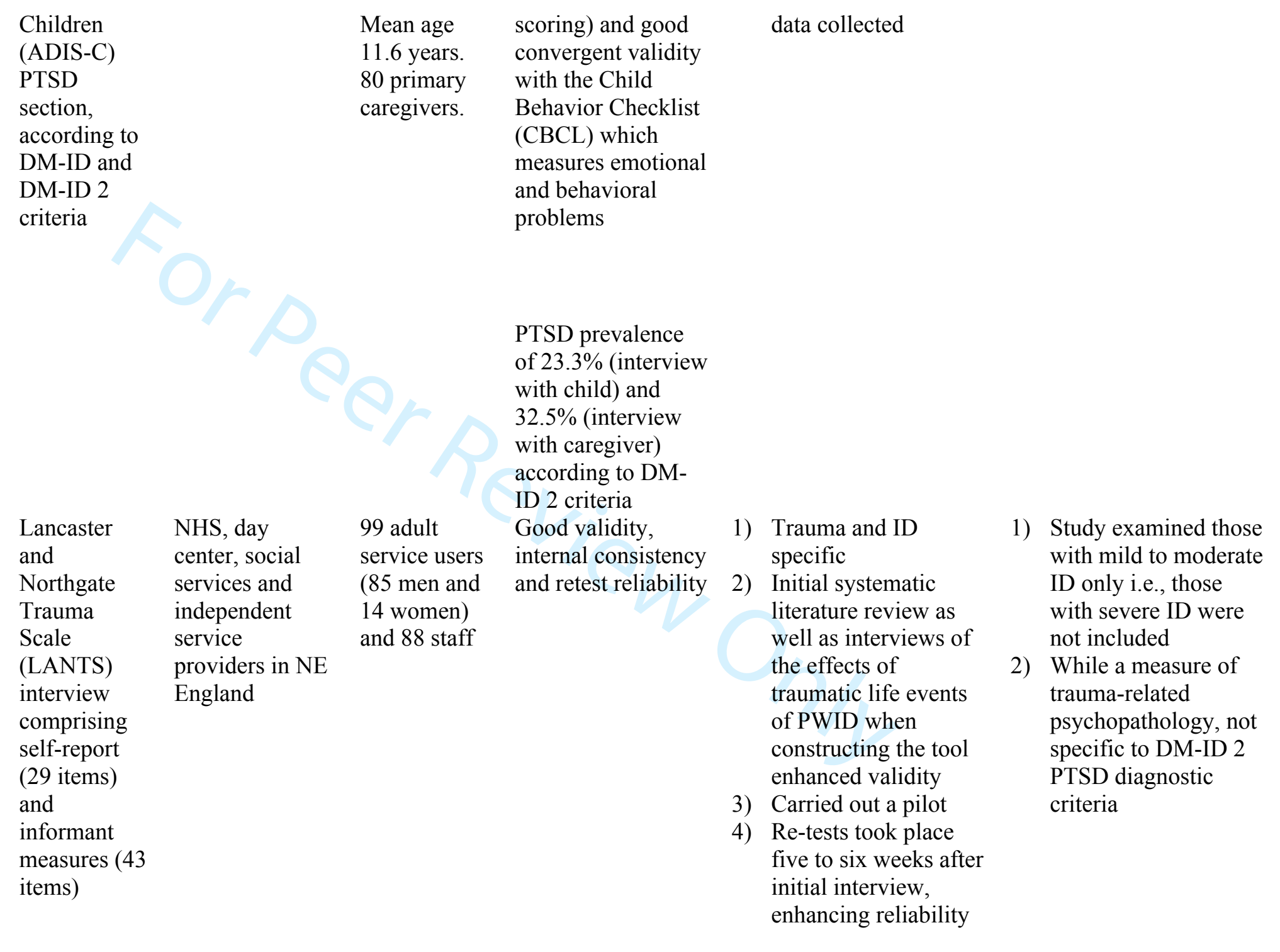


Table 2. Characteristics of PTSD prevalence studies included in this review.

\begin{tabular}{|c|c|c|c|c|c|c|c|c|}
\hline $\begin{array}{l}\text { First } \\
\text { author } \\
\text { and } \\
\text { publica } \\
\text { tion } \\
\text { date } \\
\end{array}$ & Country & $\begin{array}{l}\text { Diagnostic } \\
\text { Tool }\end{array}$ & $\begin{array}{l}\text { Population } \\
\text { incl. } \\
\text { Healthcare } \\
\text { setting }\end{array}$ & Sample size & $\begin{array}{l}\text { Results incl. } \\
\text { prevalence }\end{array}$ & Strengths & Lin & nitations \\
\hline \multirow[t]{2}{*}{$\begin{array}{l}\text { Bakken } \\
\text { et al. } \\
(2014)\end{array}$} & Norway & $\begin{array}{l}\text { Diagnostic } \\
\text { Manual - } \\
\text { Intellectual } \\
\text { Disability } \\
\text { criteria } \\
\text { interview of } \\
\text { PWID and } \\
\text { their } \\
\text { informants }\end{array}$ & $\begin{array}{l}\text { Psychiatric } \\
\text { Inpatient } \\
\text { Unit for } \\
\text { adults with } \\
\text { ID }\end{array}$ & $\begin{array}{l}\text { Five psychiatric } \\
\text { inpatients, three } \\
\text { female and two } \\
\text { male, aged between } \\
25 \text { and } 45 . \text { Three } \\
\text { with moderate } \\
\text { intellectual } \\
\text { disabilities, one } \\
\text { moderate-severe } \\
\text { and one severe } \\
\text { intellectual } \\
\text { disabilities. }\end{array}$ & $\begin{array}{l}\mathbf{1 0 0 \%} \text { PTSD } \\
\text { prevalence } \\
\text { according to } \\
\text { DM - ID criteria }\end{array}$ & $\begin{array}{l}\text { 1) Screens for PTSD in } \\
\text { moderate to severe } \\
\text { ID }\end{array}$ & 1) & Small sample size \\
\hline & & $\begin{array}{l}\text { LANTS used } \\
\text { as a } \\
\text { comparison } \\
\text { tool for } \\
\text { patients with } \\
\text { moderate ID }\end{array}$ & & & & & & \\
\hline $\begin{array}{l}\text { Cooper } \\
\text { et al. } \\
(2007)\end{array}$ & UK & $\begin{array}{l}\text { Review of } \\
\text { case notes and } \\
\text { interview of } \\
\text { participant and } \\
\text { main carer by } \\
\text { nurse and GP. } \\
\text { Diagnosis } \\
\text { based on DM- } \\
\text { ID and ICD-10 }\end{array}$ & $\begin{array}{l}\text { Population } \\
\text { identified via } \\
\text { local social } \\
\text { work } \\
\text { services and } \\
\text { specialist } \\
\text { health } \\
\text { services }\end{array}$ & $\begin{array}{l}1,023 \text { adults }(16 \text { or } \\
\text { over) with ID, } 562 \\
(54.9 \%) \text { men and } \\
461(45.1 \%) \\
\text { women. } 38.9 \% \\
\text { mild ID, } 24.2 \% \\
\text { moderate, } 18.9 \% \\
\text { severe, } 18 \% \\
\text { profound. }\end{array}$ & $\begin{array}{l}3.8 \% \text { of the } \\
\text { cohort were } \\
\text { found to have } \\
\text { anxiety } \\
\text { disorders, of } \\
\text { which } \mathbf{0 . 3 \%} \text { had } \\
\text { a clinical } \\
\text { diagnosis of } \\
\text { PTSD (three }\end{array}$ & $\begin{array}{l}\text { 1) Large sample size } \\
\text { 2) Thorough } \\
\text { methodology and } \\
\text { approach } \\
\text { 3) Includes those with } \\
\text { severe and profound } \\
\text { ID }\end{array}$ & 1) & $\begin{array}{l}\text { Sample may not be fully } \\
\text { representative e.g. those } \\
\text { with mild ID under- } \\
\text { represented (do not } \\
\text { access any services or } \\
\text { support) }\end{array}$ \\
\hline
\end{tabular}




\begin{tabular}{|c|c|c|c|c|c|c|c|c|c|}
\hline & & $\begin{array}{l}\text { criteria. } \\
\text { Further } \\
\text { interview } \\
\text { carried out by } \\
\text { psychiatrist if } \\
\text { deemed to } \\
\text { have mental } \\
\text { health } \\
\text { condition. }\end{array}$ & & & $\begin{array}{l}\text { people of the } \\
\text { total cohort of } \\
1,023) \text {. }\end{array}$ & & & & \\
\hline $\begin{array}{l}\text { Firth et } \\
\text { al. } \\
(2001)\end{array}$ & UK & $\begin{array}{l}\text { Based on case } \\
\text { notes and } \\
\text { DSM- } 4 \text { criteria }\end{array}$ & $\begin{array}{l}\text { Inpatients in } \\
\text { a specialist } \\
\text { unit for } \\
\text { young people }\end{array}$ & $\begin{array}{l}43 \text { child and } \\
\text { adolescent victims } \\
\text { of sexual abuse i.e., } \\
\text { known to have } \\
\text { experienced trauma }\end{array}$ & $\begin{array}{l}1 \text { met PTSD } \\
\text { criteria i.e., } \\
\mathbf{2 . 3 \%}\end{array}$ & 1) & $\begin{array}{l}\text { Only study } \\
\text { focussing on sexual } \\
\text { abuse } \\
\text { Includes those with } \\
\text { severe ID }\end{array}$ & $\begin{array}{l}\text { 1) } \\
\text { 2) } \\
\text { 3) }\end{array}$ & $\begin{array}{l}\text { Small sample size } \\
\text { Focusses on young } \\
\text { people only } \\
\text { Retrospective } \\
\text { examination of case } \\
\text { notes only (no interview) }\end{array}$ \\
\hline $\begin{array}{l}\text { Mevisse } \\
\mathrm{n} \text { et al. } \\
(2016)\end{array}$ & $\begin{array}{l}\text { Netherland } \\
\mathrm{s}\end{array}$ & $\begin{array}{l}\text { Adapted } \\
\text { Anxiety } \\
\text { Disorders } \\
\text { Interview } \\
\text { Schedule for } \\
\text { Children } \\
\text { (ADIS-C) } \\
\text { PTSD section, } \\
\text { according to } \\
\text { DM-ID and } \\
\text { DM-ID } 2 \\
\text { criteria }\end{array}$ & $\begin{array}{l}\text { Psychiatric } \\
\text { outpatients } \\
\text { and primary } \\
\text { caregivers } \\
\text { interviewed }\end{array}$ & $\begin{array}{l}77 \text { children (aged } \\
6-18) \text { with mild to } \\
\text { borderline ID (IQ } \\
50-85) \text { and } \\
\text { caregivers }(\mathrm{n}=80) \text {. } \\
\text { Mean age } 11.6 \\
\text { years. } 80 \text { primary } \\
\text { caregivers. }\end{array}$ & $\begin{array}{l}\text { PTSD } \\
\text { prevalence of } \\
\mathbf{2 3 . 4 \%}(18 / 77) \\
\text { was found based } \\
\text { on interviews } \\
\text { with the } \\
\text { children and } \\
\mathbf{3 2 . 5 \%}(26 / 80) \\
\text { when based on } \\
\text { interviews with } \\
\text { the caregiver. }\end{array}$ & 1) & $\begin{array}{l}\text { First study } \\
\text { validating a PTSD } \\
\text { clinical interview } \\
\text { for children with ID }\end{array}$ & $\begin{array}{l}\text { 1) } \\
\text { 2) }\end{array}$ & $\begin{array}{l}\text { Mild to borderline ID } \\
\text { only } \\
\text { Study focusses on young } \\
\text { people only }\end{array}$ \\
\hline $\begin{array}{l}\text { Ryan } \\
(1994)\end{array}$ & US & $\begin{array}{l}\text { DSM-3R } \\
\text { criteria. } \\
\text { Psychiatric } \\
\text { interview and } \\
\text { case notes } \\
\text { review. }\end{array}$ & $\begin{array}{l}\text { Referral / } \\
\text { outpatient } \\
\text { population }\end{array}$ & $\begin{array}{l}310,66 \% \text { women } \\
\text { and } 33 \% \text { men. } \\
\text { Average age } 33 . \\
\text { Moderate ID. }\end{array}$ & $\begin{array}{l}51 \text { met criteria } \\
\text { for PTSD i.e., } \\
\mathbf{1 6 . 5 \%}\end{array}$ & 1) & Large sample size & 1) & $\begin{array}{l}\text { DSM-3 criteria used, } \\
\text { PTSD and PTSD-ID } \\
\text { criteria have been } \\
\text { updated } \\
\text { Sample drawn from } \\
\text { referral population, } \\
\text { therefore may not be } \\
\text { representative of ID }\end{array}$ \\
\hline
\end{tabular}


population. Does not

assess inpatient or severe

to profound ID

population

Note. The study by Bakken et al. (2014) was excluded from the meta-analysis due to having less than 10 participants, only the remaining 4 studies were included. 
Table 3. Critical appraisal of the included studies according to STROBE criteria (Vandenbroucke et al., 2007).

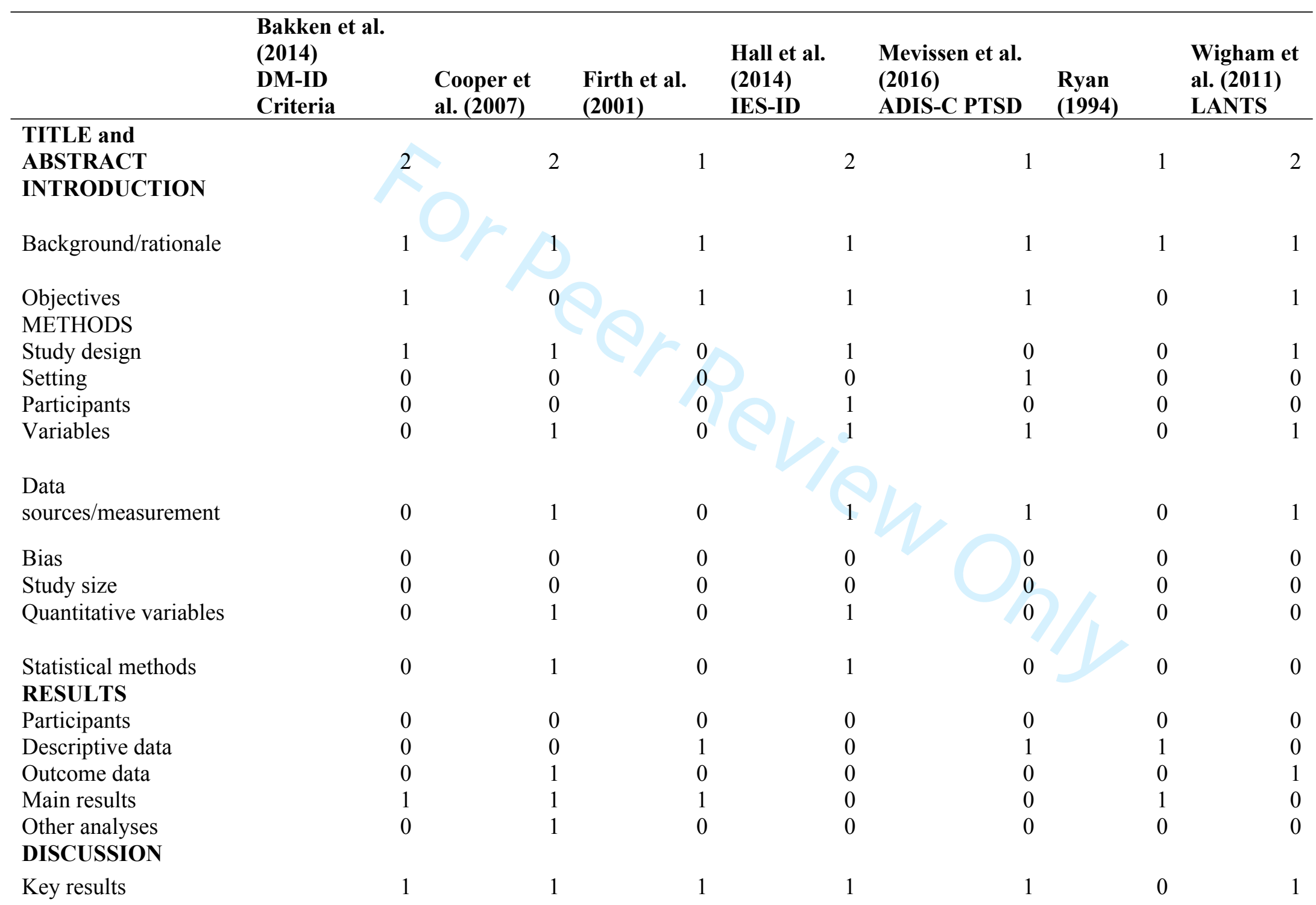




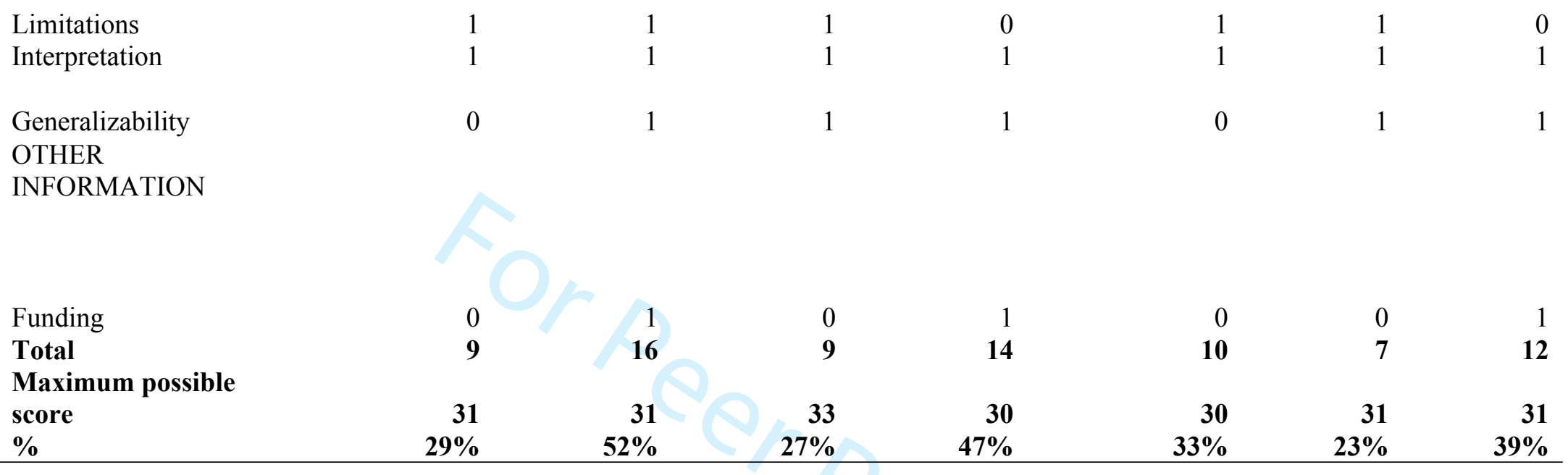


Table 4. Critical appraisal of the included studies according to the Newcastle-Ottawa scale (Modesti et al., 2016; Wells et al., 2009).

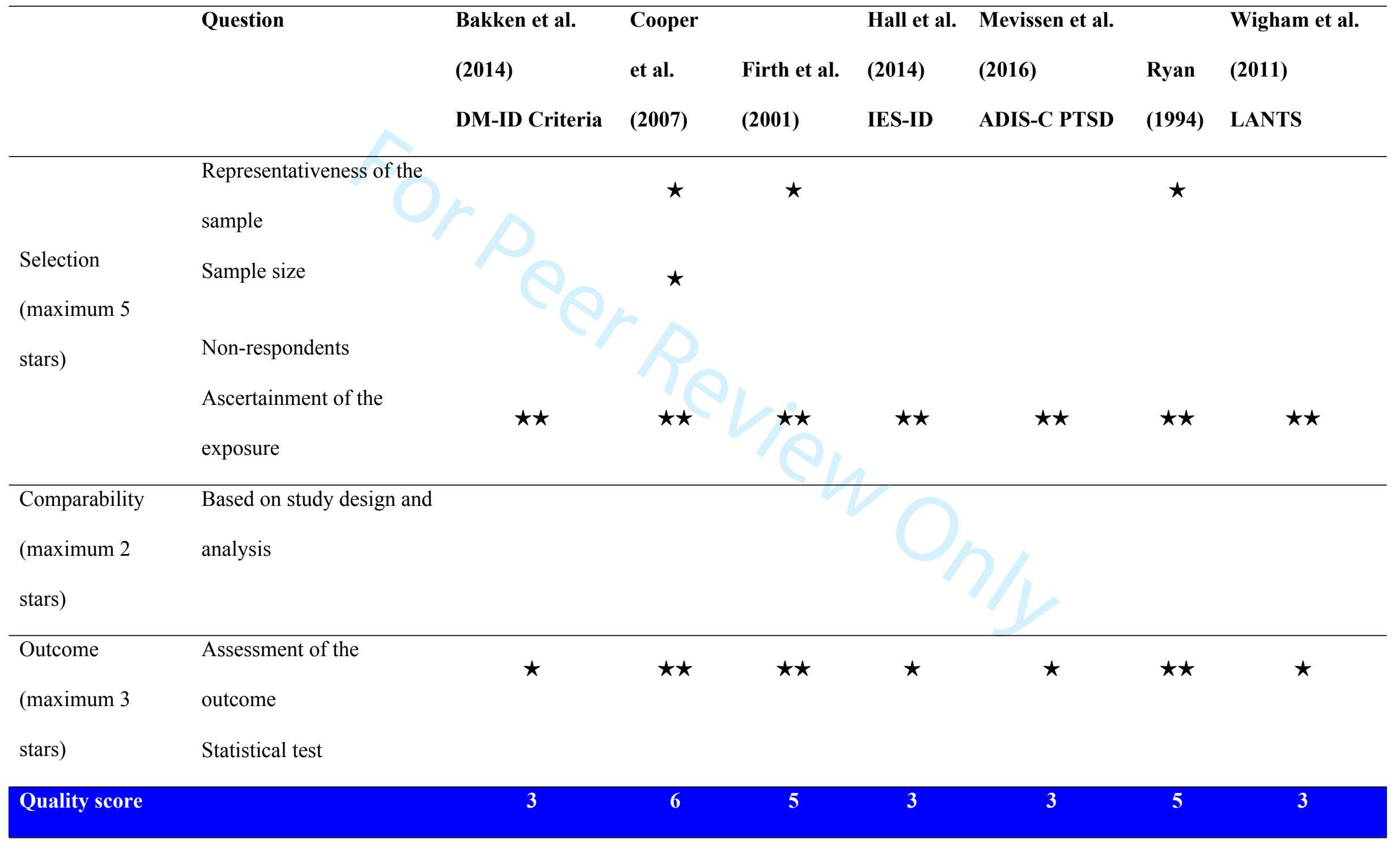


(maximum 10) 
Table 5. Impact of study characteristics on prevalence estimates for PTSD in PWID: sensitivity analysis.

\begin{tabular}{|c|c|}
\hline & Prevalence Results and $\mathrm{I}^{2}$ \\
\hline Primary Analysis & $\begin{array}{l}10,95 \% \text { CI }[0.4,20] \\
I^{2}=96.3 \\
\text { Four studies } \\
1,453 \text { participants }\end{array}$ \\
\hline $\begin{array}{l}\text { Sensitivity Analysis } \\
\text { Excluding study that retrospectively reviewed medical records to } \\
\text { screen for PTSD, used outpatients only }\end{array}$ & $\begin{array}{l}13,95 \% \text { CI }[-1.3,27] \\
I^{2}=97.5 \\
\text { Three studies } \\
1,410 \text { participants }\end{array}$ \\
\hline Studies with adult participants only & $\begin{array}{l}8,95 \% \text { CI }[-8,24] \\
\mathrm{I}^{2}=98.3 \\
\text { Two studies } \\
1,333 \text { participants }\end{array}$ \\
\hline Studies with child and adolescent participants only & $\begin{array}{l}12,95 \% \text { CI }[-8.2,33] \\
\mathrm{I}^{2}=93.6 \\
\text { Two studies } \\
120 \text { participants }\end{array}$ \\
\hline
\end{tabular}

Note. $95 \% \mathrm{CI}=95 \%$ confidence intervals; $\mathrm{I}^{2}$ assesses study heterogeneity with thresholds of $\geq 25 \%$, $\geq 50 \%$ and $\geq 75 \%$ indicating low, moderate and high heterogeneity, respectively (Higgins et al., 2003). 


\title{
Ascertainment and prevalence of post traumatic stress disorder
}

\section{(PTSD) in people with intellectual disabilities}

\author{
Abstract \\ Introduction: Post-traumatic stress disorder (PTSD) may be under-recognized in people with \\ intellectual disabilities (PWID) and reviews on appropriate screening tools and prevalence are \\ lacking. This review aims to identify PTSD screening tools for PWID and estimate the \\ prevalence of PTSD within this population. Method: Medline, PubMed, Embase, PsycINFO, \\ Cochrane, Global Health and Web of Science databases were searched (inception to October \\ 2017) to identify eligible literature. Papers were also found via manual searches of the \\ references of eligible studies. Studies were reviewed in accordance with the Preferred \\ Reporting Items for Systematic reviews and Meta-analyses (PRISMA) guidelines, subjected \\ to exclusion criteria, and quality appraised using STROBE criteria for observational studies \\ and an adapted form of the Newcastle-Ottawa scale for cross-sectional studies. Seven studies \\ were identified. Meta-analysis was carried out on the prevalence studies and heterogeneity \\ quantified using $\mathrm{I}^{2}$. Results: Three tools for screening PTSD in PWID were found: two for use \\ in adults (the Lancaster and Northgate Trauma Scale and the Impact of Event Scale - \\ Intellectual Disabilities) and the Adapted Anxiety Disorders Interview Schedule for Children \\ with PTSD. Five studies reported PTSD prevalence in PWID. The weighted pooled \\ prevalence of PTSD in PWID was found to be $10 \%, 95 \%$ CI $[0.4 \%, 19.5 \%]$, towards the \\ upper limit of estimated PTSD prevalence in the general population (5-10\%). Conclusion: \\ PTSD can be diagnosed in PWID but may go unrecognized by healthcare professionals. The \\ identified tools should be further compared and assessed for acceptability and efficacy to \\ improve the identification of PTSD in PWID. \\ Keywords: mental health, learning disabilities, PTSD, screening, prevalence
}




\section{Introduction}

Post-traumatic stress disorder (PTSD) is a mental disorder that can develop as a result of an exceptionally threatening or catastrophic event (National Institute for Health and Care Excellence, 2005). Such events include assault, road traffic accidents, sexual abuse and domestic violence (Balogh et al., 2001; National Institute for Health and Care Excellence, 2005). The Diagnostic and Statistical Manual of Mental Disorders, 5th Edition (DSM-5) diagnosis criteria include re-experiencing symptoms such as flashbacks and nightmares as well as avoidance behavior, hyperarousal and negative changes in cognitions and mood (American Psychiatric Association, 2013a). Such symptoms must last for longer than one month (American Psychiatric Association, 2013a) and typically begin within six months of the trauma (Streeruwitz, Hagger, Webb, Walker, \& Jakeman, 2009). Risk factors include neurotic personality traits, a lack of social support, a history of psychiatric problems, substance misuse and childhood abuse; twin studies also reveal genetic susceptibility (Streeruwitz et al., 2009). It is important to appreciate that people with intellectual disabilities (PWID) can also experience trauma and go on to develop PTSD (Fletcher et al., 2016). An intellectual disability is defined as a "developmental condition characterized by global impairment of intelligence and significant difficulties in socially adaptive functioning" (Cader \& Paschos, 2009, p. 202) with onset before the age of 18 (American Psychiatric Association, 2013b; Mevissen et al., 2016). Intellectual disabilities are divided into "mild" (IQ 50-69), "moderate" (IQ 35-49), "severe" (IQ 20-34) and "profound" (IQ below 20) (National Institute for Health and Care Excellence, 2014).

\section{Challenges with screening for PTSD in PWID}

Screening for PTSD in PWID presents unique challenges against a background where individuals are dealing with disability itself, issues of dependency and being part of a society that may not view them as normal (Hollins \& Sinason, 2000; Mevissen \& de Jongh, 2010; 
National Institute for Health and Care Excellence, 2015; National Institute for Health and Care Excellence, 2016). Screening is further complicated due to the considerable comorbidity of PTSD with anxiety, depression and pathological grief (McCarthy, 2001; Ryan, 1994). The unique challenges with respect to diagnosing PTSD in PWID include communication, symptom presentation and diagnostic overshadowing.

\section{Communication.}

When screening for PTSD, clinicians rely on the individual's description of their experiences and response to questions (Mevissen \& de Jongh, 2010). PWID can have receptive and expressive language limitations with reduced decision-making and cognitive capacities (Fletcher et al., 2016; Mitchell \& Doyle, 2003). Thus, the usual signs and symptoms of PTSD may not be reported or observable (National Institute for Health and Care Excellence, 2014). Additionally, PWID may try to provide answers that they deem acceptable to the clinician, so called acquiescence bias (Fletcher et al., 2016). The nature of an intellectual disability and developmental levels can also differ remarkably, leading to a wide range of communication ability and clinicians are challenged to respond to the person's individual communication style.

\section{Symptom presentation.}

The treatment setting (primary care, secondary care, community, home) and any physical health problems such as sensory impairments, can lead to differences in how mental health problems are presented (McCarthy, 2001; National Institute for Health and Care Excellence, 2014; Wigham \& Emerson, 2016).

\section{Diagnostic overshadowing.}

Diagnostic overshadowing can be defined as once clinicians have made a diagnosis of a major condition, there is a "tendency to attribute all other problems to that diagnosis, thereby leaving other co-existing conditions undiagnosed" (Neurotrauma Law Nexus, n.d.). In the 
case of PTSD in PWID, clinicians may attribute PTSD symptoms to the intellectual disability itself, for instance labeling symptoms as challenging behavior or anger (Cader \& Paschos, 2009; McCarthy, 2001; Mevissen \& de Jongh, 2010; Mevissen et al., 2016; Mitchell \& Doyle, 2003). Emotional numbing may be attributed to depression or anxiety, and flashbacks, another common symptom of PTSD, may be mistaken by the clinician as hallucinations and therefore lead to inaccurate diagnoses (Esralew, 2006).

\section{Additional factors to consider when diagnosing PTSD in PWID.}

It is widely documented that PWID are more likely to experience trauma, neglect and abuse and develop PTSD compared to the general population (Fletcher et al., 2016; Hollins \& Sinason, 2000; McCarthy, 2001; Mevissen \& de Jongh, 2010; Mevissen et al., 2016; Mitchell \& Doyle, 2003; National Institute for Health and Care Excellence, 2015; Ryan, 1994;

Wigham \& Emerson, 2016; Wigham et al., 2014). Institutional carer abuse scandals including those at Winterbourne View (Department of Health, 2012; Oakes, 2012), in the New York State developmental disability system (Halladay \& Harrington, 2015) and at Muckamore Abbey Hospital in Northern Ireland (Belfast Health and Social Care Trust, 2018) highlight the higher risk of abuse PWID can face and the importance of screening for PTSD in clinical consultations. Such abuse has included staff assaulting patients, inappropriate restraint and sexual abuse. Lower levels of intelligence are associated with a reduced ability to avoid exposure to trauma and to also cope with any PTSD effects (Mevissen \& de Jongh, 2010). Furthermore, PWID may have been subject to loss events over time such as bereavement, moving home and reduced family support and cognitive limitations or social adversity may have compromised their ability to manage stress effectively (Mevissen et al., 2016; Wigham et al., 2014).

\section{Previous research on PTSD prevalence in PWID}


Estimates of PTSD prevalence in the general population range from 5\% to $10 \%$ (Kessler, Chiu, Demler, \& Walters, 2005; Shalev, Liberzon, \& Marmar, 2017; Streeruwitz et al., 2009). Studies estimating PTSD prevalence in PWID have typically used existing measures of PTSD and tried to apply these to PWID (Mevissen \& de Jongh, 2010; Mevissen et al., 2016; Wigham et al., 2011). This approach is not ideal as such measures can involve long and complicated questionnaires as well as detailed Structured Clinical Interviews, which are not suitable for PWID, according to their intellectual ability. As such, there is a lack of research on psychometrically validated PTSD screening tools specific to the ID population (Mevissen \& de Jongh, 2010; Mevissen et al., 2016; Wigham et al., 2011). As a result of the lack of screening tools, there is little information about prevalence rates (Mevissen $\&$ de Jongh, 2010) with the risk that PTSD is under-recognized in PWID (Mitchell et al., 2006). Undiagnosed and untreated PTSD can lead to a reduced quality of life, impaired emotional, social and physical development as well as higher costs of care in the long-run (Mevissen et al., 2016). The National Institute for Health and Care Excellence (NICE) acknowledges that "mental health problems are often overlooked and therefore untreated in people with learning disabilities" (National Institute for Health and Care Excellence, 2016, p. 33). Although general guidance on the assessment and management of mental health problems in PWID is provided, specific guidance on PTSD screening is lacking (National Institute for Health and Care Excellence, 2016).

\author{
Aims of the review \\ The current review seeks to provide an update to the literature, following a 2010 \\ systematic review carried out by Mevissen and de Jongh (2010) which did not find any \\ diagnostic tools specific for PTSD in PWID, aside from DSM-4 PTSD criteria adapted for \\ PWID (DM-ID, Diagnostic Manual - Intellectual Disability). Furthermore, the review found \\ only three studies examining the prevalence of PTSD in PWID. Prevalence estimates varied
}


widely - from $2.5 \%$ to $60 \%$ (Firth et al., 2001; Mitchell et al., 2006; Ryan, 1994). However none of the studies identified in the review used ID-specific screening tools or tools validated for use in PWID and a pooled prevalence estimate was not provided (Mevissen \& de Jongh, 2010). This systematic review therefore has two aims:

1) Identification of screening tools for the detection of PTSD symptoms in PWID.

2) Estimation of the prevalence of PTSD in PWID.

\section{Method}

\section{Literature search strategy}

Computerized searches of the Medline, Embase, PsycINFO and Global Health databases were conducted by the first author from inception of each database to 29th October 2017 using the Ovid SP interface. The PubMed, Cochrane and Web of Science databases were searched separately. The pre-defined search terms together with the Boolean operators $O R$ and $A N D$ entered into the Title field for the two searches are detailed below.

\section{Search 1.}

"PTSD" OR "post-traumatic stress disorder" OR "post traumatic stress disorder" OR trauma OR abuse OR "life events" OR "environmental stressors" OR "stress disorder", AND

\section{Search 2.}

"learning disabilit*" OR "intellectual disabilit*" OR "developmental disabilit*" OR "learning difficult*" OR "intellectual difficult*" OR "developmental difficult*" OR "learning impair*" OR "intellectual impair*" OR "developmental impair*" OR "mental retardation" OR "mental handicap"

Learning disabilities was included as a search term in Search 2 to include studies concerning PWID who may have been incorrectly noted as having a learning disability. The terms learning disability and intellectual disability are not interchangeable and can be 
confused reflecting a changing international context (Cluley, 2017). Thus by including learning disabilities in the search terms, it is possible to carry out a more complete search and capture studies that may have included PWID that were incorrectly identified as having a learning disability. This approach would also include studies comprising both PWID and those with learning disabilities and is in line with the previous systematic review by Mevissen and de Jongh (2010) where this search term was included. Searches of English-language publications only were carried out, enhanced by examination of the references of the included studies and duplicates were removed. The search was replicated by the fourth author with the same results.

The inclusion criteria were: i) peer-reviewed journal articles in English; ii) people with intellectual disabilities, clinically verified according to DSM criteria; iii) observational study design; iv) PTSD defined via DSM diagnostic criteria, a research diagnostic tool or a validated screening tool; and v) either narrative studies on PTSD screening tools specific to PWID or studies examining PTSD prevalence within the ID population (prevalence levels reported as the number of participants meeting criteria for PTSD or a percentage from which the number of participants meeting this criteria could be calculated). Articles were excluded if they: i) related to PTSD treatment or prevention; ii) examined substance abuse amongst PWID; iii) were systematic or qualitative reviews; iv) were conference or meeting abstracts without corresponding full-length journal articles; and v) were "grey" literature (rather than being published in peer-reviewed scientific journals). For the meta-analysis, studies with fewer than 10 participants were excluded both due to the low quality nature of many case reports and because studies with such small sample sizes may distort the overall findings by over-estimating effect sizes (Levine, Asada, \& Carpenter, 2009).

\section{Study selection and data extraction}


A structured spreadsheet was used by the first author to extract the following information: study title, abstract, publication year, author and country. Titles and abstracts of the results of the search were reviewed and screened for suitability and relevance using an inclusion/exclusion process. The full text of articles that met the inclusion criteria were obtained.

\section{Quality appraisal}

STROBE (Strengthening the Reporting of Observational Studies in Epidemiology) criteria for observational studies (Vandenbroucke et al., 2007) and an adapted form of the Newcastle-Ottawa scale for cross-sectional studies (Modesti et al., 2016; Wells et al., 2009) were used by the first and fourth authors independently to evaluate the quality of the papers; any disagreements were resolved through discussion. Two tools were used to provide a more detailed quality appraisal of the studies and while both are suitable for observational studies, the Newcastle-Ottawa scale has a focus on sample selection while the STROBE statement is a detailed checklist balanced across the key sections of a study. The statement consists of a 22item checklist with each component scored, relating to the title (needs to indicate the study's design), abstract (informed and balanced summary), introduction (clear rationale and specific objectives), methods (study design and setting described, participants with clear eligibility criteria, bias examined, appropriate study size and statistical methods), results (descriptive data regarding the study participants, main results and analysis carried out), discussion (clear summary of key results, limitations discussed and generalizability of findings) and source of funding provided (Vandenbroucke et al., 2007). The Newcastle-Ottawa scale, a collaboration between the Universities of Newcastle, Australia and Ottawa, Canada uses a "star system" in which a study is scored out of a maximum of 10 on three areas: 1) the selection of study groups (satisfactory sample size and representativeness, adequate response rate), 2) study design and analysis and 3) ascertainment of the outcome of interest (outcome assessment, 
appropriate statistical analysis and clearly described) (Modesti et al., 2016; Wells et al., 2009).

\section{Statistical analysis}

Meta-analysis with $95 \%$ confidence intervals (CI) was performed to estimate the weighted pooled prevalence rates of PTSD in PWID. Weighted prevalence rates and associated CI for the prevalence rates were calculated in each study and then they were pooled using the metan command in Stata (version 11.0) (Kontopantelis \& Reeves, 2010). Heterogeneity in meta-analysis examines whether the effects found in individual studies are similar enough to be confident that the combined effect of all studies is a meaningful description of the set of studies (Higgins et al., 2003). Heterogeneity describes more variation between the studies than would be expected by chance alone and is assessed using $\mathrm{I}^{2}$ (examines the weighted sum of differences between individual study effects and the pooled effect across studies) with thresholds of $\geq 25 \%, \geq 50 \%$ and $\geq 75 \%$ indicating low, moderate and high heterogeneity, respectively (Higgins et al., 2003). All analyses were conducted using a random effects model as significant heterogeneity was expected across the studies. Sensitivity analyses explored whether prevalence estimates were influenced by the study design. Planned sensitivity analyses included: i) excluding studies that retrospectively reviewed medical records to screen for PTSD so only those studies where screening was carried out via interview were included and ii) separate analyses on studies with adult participants compared to studies of children and adolescents.

\section{Search findings and study characteristics}

Figure 1 summarizes the study selection process. The total number of citations retrieved was 972 . The titles and abstracts were screened for relevance and 28 full-text articles were assessed for eligibility. This final screening process found that 21 did not meet the eligibility criteria; a full breakdown of the reasons for exclusion are provided in Figure 1. Therefore, a 
total of seven studies met the inclusion criteria and quality appraisal, four examining prevalence rates and three describing and examining PTSD screening tools for PWID (one of which also provided prevalence figures). One of the four prevalence studies was excluded from the meta-analysis due to having less than 10 participants (Bakken et al., 2014).

\section{Descriptive characteristics of the included studies}

The three studies examining PTSD screening tools in PWID were based on a total of 219 participants (range 40-99). Two of the studies were conducted in the UK and one in the Netherlands. All studies were observational and are summarized in Table 1 (Appendix A). The study by Mevissen et al. (2016) also provided a PTSD prevalence estimate based on the 80 participants in their study.

The four studies that examined PTSD prevalence in PWID were based on a total sum of 1,381 participants. The number of participants ranged from five to 1,023 . Two of the studies were conducted in the UK, and one each in the US and in Norway. Measures used to screen for PTSD included semi-structured interviews and a review of case notes, analyzed according to either DSM-3R, DSM-4 or DM-ID criteria. The studies are summarized in Table 2 (Appendix A).

\section{Results}

\section{Screening tools}

The three identified PTSD screening tools psychometrically appropriate for PWID are the Lancaster and Northgate Trauma Scale (LANTS) (Wigham et al., 2011), the Impact of Events Scale - Intellectual Disabilities (IES-ID) (Hall, Jobson, \& Langdon, 2014) and the Adapted Anxiety Disorders Interview Schedule for Children (ADIS-C PTSD) (Mevissen et al., 2016). Further details about the studies including the sample characteristics, results as well as strengths and limitations are provided in Appendix A. 
The LANTS is a 29-item self-report (with four Likert scale response options) with a 43item informant measure of the effects of traumatic life events on PWID. The scale was developed for adults with mild to moderate ID and the informant measure provides a useful addition which can be completed by carers to provide further screening information. The key drawbacks of this tool include it being a rather long item list for both the self-report and informant measures and although the tool measures trauma-related psychopathology, it does not enable a diagnosis of PTSD based on standard diagnostic criteria. However it could be adapted to do so (S. Wigham, personal communication, November 21, 2017). The IES-ID (Hall et al., 2014) is also designed for adults with mild ID but in contrast to the LANTS, is an adapted form of the Impact of Events Scale (Weiss, 2007) and is a shorter self-report questionnaire at 22 items and provides three rather than four Likert scale response options for PWID to complete. There is no informant element and the tool corresponds directly with DMID diagnostic criteria of avoidance, intrusion and hyperarousal. Finally, the ADIS-C PTSD (Mevissen et al., 2016) is the first screening tool assessing PTSD specifically in children with ID. The tool accords with DM-ID 2 PTSD diagnostic criteria, has a caregiver version and could be adapted to an adult version (Mevissen-Renckens, 2017). A drawback is that the instrument lacks a version for children with more severe ID; it is recommended that the caregiver version of the ADIS-C PTSD is used for this purpose (Mevissen-Renckens, 2017).

\section{Prevalence of PTSD or PTSD symptoms in PWID}

Data from 1,453 participants in four studies contributed to the meta-analysis. The weighted pooled prevalence of PTSD in PWID was 10\%, 95\% CI [0.4\%, 19.5\%], see Figure 2. However, there were large variations across the studies in the reported rates of PTSD, ranging from $0.3 \%$ to $23.4 \%$ and heterogeneity was high $\left(\mathrm{I}^{2}=96.3 \%\right)$. Differences in the diagnostic method (interview vs. review of case notes), the age of the participants (children and adolescents vs. adults) and the treatment setting (inpatient vs. community) could drive the 
variation. Furthermore, different versions of the DSM PTSD criteria were used which reduces the ability to compare across the studies and adds a limitation to pooling the prevalence figures. It is also important to bear in mind that having a positive screen for PTSD symptoms does not necessarily equate to being diagnosed with PTSD according to formal diagnostic criteria (American Psychiatric Association, 2013a). Screening tools are not the same as receiving a formal diagnosis from a structured clinical interview; while the tools may pick up PTSD symptoms in an individual, these may not meet the full diagnostic criteria of PTSD (American Psychiatric Association, 2013a). Ryan (1994) used DSM-3 criteria and benefitted from a relatively large sample size of 310 , finding a prevalence of $16.5 \%$; however the sample did not include inpatients nor those with severe to profound ID. Firth et al. (2001) (child and adolescent inpatient population, $n=43)$ and Cooper et al. (2007) (1,023 outpatients) used DSM-4 diagnostic criteria and found prevalence rates of $2.3 \%$ and $0.3 \%$ respectively. Mevissen et al. (2016) examined prevalence as part of investigating the psychometric properties of the PTSD screening tool, finding a prevalence of $23.3 \%$ (based on interviews with the children and adolescents) and 32.5\% (based on interviews with the caregiver).

The prevalence study carried out by Bakken et al. (2014) (excluded from the meta analysis due to having less than 10 participants) comprised interviews of five PWID from a psychiatric inpatient unit in Norway and their informants according to the DM-ID (Diagnostic Manual Intellectual Disability) criteria (Fletcher et al., 2016). The six criteria, derived from DSM-TRIV, include confirmation of exposure to a traumatic event which is persistently reexperienced, avoidance of stimuli associated with the trauma, increased arousal, distress and impairment in functioning with symptom duration of more than 1 month. Although this study has a small sample size, and found a PTSD prevalence rate of $100 \%$, its key strength is that it screened for PTSD in individuals with moderate to severe ID.

\section{Sensitivity analysis}


Table 5 shows prevalence estimates according to each sensitivity analysis, in comparison with the primary analysis. On excluding the study by Firth et al. (2001) who carried out a retrospective review of case notes of inpatients without interviews, prevalence increased to $13 \%$ and heterogeneity to $97.5 \%$ (i.e., increased variation between the studies in this subset, more than would be expected by chance alone). The other studies carried out interviews with patients from a community setting. For the two studies with adult participants only, prevalence decreased to $8 \%$ but heterogeneity increased to $98.3 \%$ compared with the primary analysis. While for the two studies with child and adolescent participants only (Firth et al., 2001, Mevissen et al., 2016), prevalence increased to $12 \%$ and heterogeneity decreased to $93.6 \%$ compared with the primary analysis (implying reduced variation amongst the studies in this subset). Thus, the results indicate a higher prevalence of PTSD in children and adolescents with intellectual disabilities compared to adults. However, this could be the result of a measurement issue given the small number (only two studies covering each population) and low quality of the identified studies employing varied assessment tools, as one would expect PTSD at childhood and adolescence to continue into adulthood.

\section{Critical appraisal of the included studies}

Percentage scores under the STROBE criteria (Vandenbroucke et al., 2007) ranged from $23 \%$ to $52 \%$ (table 3, Appendix A), which helps to contextualize the present study's findings, highlights the limitations of the research found and need for further high-quality studies. The lower scored studies included Ryan (1994) (23\%), Firth et al. (2001) (27\%) and Mevissen et al. (2016) (33\%) and did not meet one or more of the following criteria: including key elements of the study design early in the paper, describing the setting, providing eligibility criteria, describing efforts to address bias or explain how the study size was arrived at, describing all statistical methods, use of a flow diagram and providing the source of funding. The higher scoring studies of Wigham et al. (2011) (39\%), Hall et al. (2014) (47\%) and 
Cooper et al. (2007) (52\%) did not describe the setting adequately, nor efforts to address sources of bias, how the study size was arrived at nor the characteristics of study participants and did not use a flow diagram. According to the Newcastle-Ottawa scale (Modesti et al., 2016), Cooper et al. (2007) scored 6/10 with a representative sample, good sample size, use of a validated screening tool and good outcome assessment, although lacking in comparability of outcome groups and not describing statistical tests adequately. Ryan (1994) and Firth et al. (2001) scored 5/10 due to reduced sample sizes while the remaining studies scored 3/10 due to reduced sample representativeness and the self-reporting of outcomes. The results are summarized in table 4 (Appendix A).

\section{Discussion}

\section{Summary of the main findings}

In this review we identified several new studies that indicate there is emerging interest in PTSD and its diagnosis in PWID, providing an update to the last systematic review on PTSD prevalence and screening carried out by Mevissen and de Jongh (2010). Three screening tools were found that can aid the diagnosis of PTSD in PWID. These are the Lancaster and Northgate Trauma Scale (Wigham et al., 2011), the Impact of Event Scale Intellectual Disabilities (Hall et al., 2014) and the Adapted Anxiety Disorders Interview Schedule for Children (Mevissen et al., 2016). Studies show a wide variation in the prevalence of PSTD in PWID. We carried out a meta-analysis of prevalence, finding a weighted pooled prevalence of $10 \%$. This is towards the upper limit of PTSD prevalence in the general population, estimated at 5-10\% (Kessler et al., 2005; Shalev, Liberzon, \& Marmar, 2017; Streeruwitz et al., 2009).

\section{Implications for researchers, policy makers and clinicians}


Previous studies on screening for PTSD symptoms in PWID have largely been based on DSM criteria that have not been adapted to people with intellectual disabilities (Cooper et al. 2007; Firth et al., 2001; Mitchell et al., 2006; Ryan, 1994). Given the potential communication difficulties of PWID and diagnostic overshadowing, this approach is not ideal. Symptoms of PTSD in PWID may present as challenging behavior, for instance, aggression, disruptive behavior, self-harm, agitation, distractibility, sleep problems or depressed mood (McCarthy, 2001). Self injury and social withdrawal are also more prevalent (Bakken et al., 2014). PWID can react to trauma differently depending on the level of their intellectual disability (Mitchell et al., 2006). The three identified screening tools with their use of informant measures and Likert scales are an important step in screening for PTSD symptoms in PWID and can aid the diagnosis of PTSD. Further research should be carried out on these tools to examine their efficacy and consistency as well as digital version options which may assist those with more severe cognitive limitations (Callaghan et al., 2003). In addition, as with any screening tool, there is a risk of obtaining false positive and false negative results and therefore, inappropriate treatment may be offered or necessary treatment withheld. As part of refining the screening tools, they should be examined for their sensitivity and specificity.

Following a diagnosis of PTSD, effective treatment should be implemented. In the general population, Eye Movement Densitization and Reprocessing (EMDR) therapy, Cognitive Behavioural Therapy (CBT) and pharmacological therapy have been shown to be effective in PTSD treatment (National Institute for Health and Care Excellence, 2005; Streeruwitz et al., 2009; World Health Organisation, 2013). It is not yet clear whether such treatment would be effective for PWID who require it although research is ongoing (Giltaij, 2004; Mevissen et al., 2016; Tharner, 2006) and effective treatments for trauma in PWID should continue to be sought. 


\section{Strengths and limitations}

This paper provides an update to the literature, calculating a pooled prevalence of PTSD in PWID and identifies three PTSD screening tools for PWID. This review was performed and reported according to PRISMA (Preferred Reporting Items for Systematic reviews and Meta-analyses) guidance (Liberati et al., 2009), which aims to ensure that systematic reviews and meta-analyses are reported clearly and accurately.

The review has some limitations. First, it is clear that in order to obtain accurate prevalence data on PTSD in PWID, it is key to have accurate PTSD screening tools. The included studies varied widely in terms of research design, participants and measures used to screen for PTSD in PWID. The studies achieved low scores on quality appraisal, which helps to contextualize the present study's findings and highlights the limitations in the research found. Clearly, additional and higher-quality research investigating this topic needs to be conducted. In order to achieve a higher quality, research should use validated screening tools with a large sample size (at least 10 participants) and detail should be provided regarding the study design, statistical methods and potential sources of bias, incorporating diagrams / flow charts to aid explanations where appropriate. Second, it could be argued that meta-analysis of the prevalence studies is inappropriate given the high amount of variation, more than that expected due to chance i.e., there is high heterogeneity and the data may be more suited to a narrative synthesis. However, meta-analysis has the advantage of allowing direct comparison and the assignment of weights across studies; as a result, the weighted pooled prevalence may be at least as important as the individual prevalence study estimates. The large heterogeneity was accounted for by applying random effects models in pooling the prevalence rates across the studies. Sensitivity analyses also helped to identify sources of heterogeneity. Third, searches were restricted to studies in English only which excludes studies that may have met the inclusion criteria but were written in a different language. Fourth, grey literature was also 
excluded as it was considered highly unlikely that high quality studies on PTSD screening and prevalence in PWID would not have been published in peer-reviewed journals. However, we cannot eliminate the possibility that by excluding grey literature, undetected selection bias has been introduced.

\section{Summary}

Clinicians, families and carers should be aware that PWID are more susceptible to experiencing traumatic events, which may lead to higher levels of PTSD compared with the general population. PWID presenting with mood disorders or challenging behavior may in fact be experiencing PTSD symptoms. Training courses, education programs and national policy can help inform healthcare professionals about how trauma can present in PWID. Annual health checks of PWID may provide an opportunity at public health level to enquire whether any traumatic events have occurred in the past year thus ensuring that prompt referral to appropriate services for further diagnosis and treatment is initiated (National Institute for Health and Care Excellence, 2014; National Institute for Health and Care Excellence, 2016). Screening at regular intervals using appropriate tools has been shown to be effective in the general population following major disasters (National Institute for Health and Care Excellence, 2005); PWID, who are at increased risk of experiencing trauma, should not be forgotten in such screening programs. 


\section{References}

American Psychiatric Association. (2013a). Diagnostic and statistical manual of mental disorders (5th ed.). Washington, DC: American Psychiatric Publishing.

American Psychiatric Association. (2013b). DSM-5 Intellectual Disability Fact Sheet. DSM5. Washington, DC. Retrieved from https://www.psychiatry.org/.../Practice/DSM/APA_DSM-5-Intellectual-Disability.pdf

Bakken, T. L., Kildahl, A. N., Gjersøe, V., Matre, E., Kristiansen, T., Ro, A., ... Høidal, S. H. (2014). Identification of PTSD in adults with intellectual disabilities in five patients in a specialised psychiatric inpatient unit. Advances in Mental Health and Intellectual Disabilities, 8(2), 91-102. https://doi.org/10.1108/AMHID-01-2013-0002

Balogh, R., Bretherton, K., Whibley, S., Berney, T., Graham, S., Richold, P., ... Firth, H. (2001). Sexual abuse in children and adolescents with intellectual disability. Journal of Intellectual Disability Research, 45(3), 194-201. https://doi.org/10.1046/j.13652788.2001.00293.x

Belfast Health and Social Care Trust. (2018). Muckamore Abbey Statement. Retrieved December 23, 2018, from http://www.belfasttrust.hscni.net/3159.htm

Cader, S., \& Paschos, D. (2009). Learning disability. In S. Stringer, L. Church, S. Davison, \& M. Lipsedge (Eds.), Psychiatry P.R.N. (pp. 201-208). New York: Oxford University Press.

Callaghan, M. A. C. O., Murphy, G. H., \& Clare, I. C. H. (2003). Symptoms of Abuse in Adults with Severe Learning Disabilities Final Report to the Dept of Health. Retrieved from https://www.kent.ac.uk/tizard/research/documents/DoH_Abuse_report_2006.pdf Cluley, V. (2017). From “Learning disability to intellectual disability"- Perceptions of the increasing use of the term " intellectual disability" in learning disability policy, research and practice. British Journal of Learning Disabilities, (October), 24-32.

https://doi.org/10.1111/bld.12209 
Esralew, L. (2006). PTSD and related stress disorders in persons with developmental disabilities (Vol. NADD IX). Retrieved from http://thenadd.org/modal/bulletins/v9n1a3 .htm

Firth, H., Balogh, R., Berney, T., Bretherton, K., Graham, S., \& Whibley, S. (2001). Psychopathology of sexual abuse in young people with intellectual disability. Journal of Intellectual Disability Research, 45(3), 244-252. https://doi.org/10.1046/j.13652788.2001.00314.x

Fletcher, R. J., Barnhill, J., McCarthy, J., \& Strydom, A. (2016). From DSM to DM-ID. Journal of Mental Health Research in Intellectual Disabilities, 9(3), 189-204. https://doi.org/10.1080/19315864.2016.1185324

Giltaij, H. (2004). Alsof er een stofzuiger door mijn hoofd is gegaan. EMDR bij mensen met een visuele en verstandelijke beperking. [As if a vacuum cleaner went through my head. EMDR in people with visual and intellectual disabilities]. Tijdschrift Voor Kinder-\& Jeugdpsychotherapie, 3, 81-97.

Hall, J. C., Jobson, L., \& Langdon, P. E. (2014). Measuring symptoms of post-traumatic stress disorder in people with intellectual disabilities: The development and psychometric properties of the Impact of Event Scale-Intellectual Disabilities (IES-IDs). British Journal of Clinical Psychology, 53(3), 315-332. https://doi.org/10.1111/bjc. 12048

Halladay, P. M., \& Harrington, C. (2015). Scandals of abuse: Policy responses in intellectual disabilities. International Journal of Sociology and Social Policy, 35, 107-124. https://doi.org/10.1108/IJSSP-12-2013-0117

Health, D. of. (2012). Transforming care: A national response to Winterbourne View Hospital. https://doi.org/Gateway reference 18348

Higgins, J. P. T., Thompson, S. G., Deeks, J. J., \& Altman, D. G. (2003). Measuring 
inconsistency in meta-analyses. BMJ : British Medical Journal, 327(7414), 557-560. https://doi.org/10.1136/bmj.327.7414.557

Hollins, S., \& Sinason, V. (2000). Psychotherapy, learning disabilities and trauma : new perspectives. British Journal of Psychiatry, 176, 32-36. https://doi.org/10.1192/bjp.176.1.32

Kessler, R., Chiu, W., Demler, O., \& Walters, E. (2005). Prevalence, severity, and comorbidity of 12-month DSM-IV disorders in the national comorbidity survey replication. Archives of General Psychiatry, 62, 617-627.

Kontopantelis, E., \& Reeves, D. (2010). The metaan command: random effects meta-analysis. The Stata Journal, 10(3), 395-407.

Levine, T., Asada, K. J., \& Carpenter, C. (2009). Sample Sizes and Effect Sizes are Negatively Correlated in Meta- Analyses : Evidence and Implications of a Publication Bias Against NonSignificant Findings. Communication Monographs, 76(3), 286-302. https://doi.org/10.1080/03637750903074685

Liberati, A., Altman, D. G., Tetzlaff, J., Mulrow, C., Gøtzsche, P. C., Ioannidis, J. P. A., ... Moher, D. (2009). The PRISMA statement for reporting systematic reviews and metaanalyses of studies that evaluate health care interventions: Explanation and elaboration. PLoS Medicine, 6(7). https://doi.org/10.1371/journal.pmed.1000100

McCarthy, J. (2001). Post-traumatic stress disorder in people with learning disability. Advances in Psychiatric Treatment, 7(3), 163-169. https://doi.org/10.1192/apt.7.3.163

Mevissen-Renckens, E. H. M. (2017). Assessment and treatment of posttraumatic stress disorder in individuals with intellectual disabilities. ( $\mathrm{PhD}$ thesis). Retrieved from UvADARE (Digital Academic Repository).

Mevissen, L., \& de Jongh, A. (2010). PTSD and its treatment in people with intellectual disabilities. A review of the literature. Clinical Psychology Review, 30(3), 308-316. 
https://doi.org/10.1016/j.cpr.2009.12.005

Mevissen, L., Didden, R., \& Jongh, A. De. (2016). Assessment and Treatment of PTSD in People with Intellectual Disabilities. In C. R. Martin, V. R. Preedy, \& V. B. Patel (Eds.), Comprehensive Guide to Post-Traumatic Stress Disorder. Switzerland: Springer International Publishing. https://doi.org/10.1007/978-3-319-08613-2

Mevissen, L., Didden, R., Korzilius, H., \& de Jongh, A. (2016). Assessing posttraumatic stress disorder in children with mild to borderline intellectual disabilities. European Journal of Psychotraumatology, 7. https://doi.org/10.3402/ejpt.v7.29786

Mitchell, A., Clegg, J., \& Furniss, F. (2006). Exploring the meaning of trauma with adults with intellectual disabilities. Journal of Applied Research in Intellectual Disabilities, 19(2), 131-142. https://doi.org/10.1111/j.1468-3148.2005.00235.x

Mitchell, D., \& Doyle, C. (2003). Post-traumatic stress disorder and people with learning disabilities. Journal of Learning Disabilities, 7(1), 23-33.

Modesti, P. A., Reboldi, G., Cappuccio, F. P., Agyemang, C., Remuzzi, G., \& Rapi, S. (2016). Panethnic Differences in Blood Pressure in Europe : A Systematic Review and Meta- Analysis. PLoS One, 11(1), 1-21. https://doi.org/10.1371/journal.pone.0147601

National Institute for Health and Care Excellence. (2005). Post-traumatic stress disorder : management. Retrieved from https://www.nice.org.uk/guidance/cg26

National Institute for Health and Care Excellence. (2014). Mental health problems in people with learning disabilities: prevention, assessment and management. Retrieved from https://www.nice.org.uk/guidance/GID-CGWAVE0684/documents/mental-healthproblems-in-people-with-learning-disabilities-scope-consultation-comments-table2 National Institute for Health and Care Excellence. (2015). Challenging behaviour and learning disabilities: prevention and interventions for people with learning disabilities whose behaviour challenges. Retrieved from https://www.nice.org.uk/guidance/ng11 
National Institute for Health and Care Excellence. (2016). Mental health problems in people with learning disabilities: prevention, assessment and management, (July), 1-38. Retrieved from https://www.nice.org.uk/guidance/GIDCGWAVE0684/documents/mental-health-problems-in-people-with-learning-disabilitiesscope-consultation-comments-table2

Neurotrauma Law Nexus. (n.d.). Neurotrauma Law Nexus. Retrieved April 6, 2019, from http://www.neurolaw.com/neuroglossary/

Oakes, P. (2012). Crash: what went wrong at Winterbourne View? Journal of Intellectual Disabilities : JOID, 16(3), 155-62. https://doi.org/10.1177/1744629512449095

Ryan, R. (1994). Posttraumatic stress disorder in persons with developmental disabilities. Community Mental Health Journal, 30(1), 45-54. https://doi.org/10.1007/BF02188874

Shalev, A., Liberzon, I., \& Marmar, C. (2017). Post-Traumatic Stress Disorder. New England Journal of Medicine, 376(25), 2459-2469. https://doi.org/10.1056/NEJMra1612499

Streeruwitz, A., Hagger, M., Webb, S., Walker, D., \& Jakeman, N. (2009). Anxiety, obsessions, and reactions to stress. In S. Stringer, L. Church, S. Davison, \& M. Lipsedge (Eds.), Psychiatry P.R.N (pp. 147-166). New York: Oxford University Press.

Tharner, G. (2006). Over de toepassing van EMDR bij de behandeling van mensen met een lichte verstandelijke beperking. [About the application of EMDR in the treatment of people with a mild intellectual disability]. In In Robert Didden (Ed.), In perspectief. Gedragsproblemen, psychiatrische stoornissen en lichte verstandelijke beperking. Bohn Stafleu van Loghum. (pp. 145-168).

Vandenbroucke, J. P., Von Elm, E., Altman, D. G., Gøtzsche, P. C., Mulrow, C. D., Pocock, S. J., ... Egger, M. (2007). Strengthening the Reporting of Observational Studies in Epidemiology (STROBE): Explanation and elaboration. PLoS Medicine, 4(10), 16281654. https://doi.org/10.1371/journal.pmed.0040297 
Weiss, D. (2007). The Impact of Event Scale-Revised. In J. Wilson \& T. Keane (Eds.), Assessing psychological trauma and PTSD: a practitioner's handbook (2nd ed., pp. 168-189). New York: Guilford Press. https://doi.org/10.1001/jama.2016.8474

Wells, G., Shea, B., O’Connell, D., Peterson, J., Welch, V., Losos, M., \& Tugwell, P. (2009). The Newcastle-Ottawa Scale (NOS) for assessing the quality of nonrandomised studies in meta-analyses. Retrieved from http://www.ohri.ca/programs/clinical_epidemiology/oxford.asp

Wigham, S., \& Emerson, E. (2016). Trauma and life events in adults with intellectual disability. Current Developmental Disorders Reports, 2(2), 93-99. Retrieved from https://link.springer.com/article/10.1007\%2Fs40474-015-0041-y

Wigham, S., Hatton, C., \& Taylor, J. L. (2011). The effects of traumatizing life events on people with intellectual disabilities: A systematic review. Journal of Mental Health Research in Intellectual Disabilities, 4(1), 19-39.

https://doi.org/10.1080/19315864.2010.534576

Wigham, S., Hatton, C., \& Taylor, J. L. (2011). The Lancaster and Northgate Trauma Scales (LANTS): The development and psychometric properties of a measure of trauma for people with mild to moderate intellectual disabilities. Research in Developmental Disabilities, 32(6), 2651-2659. https://doi.org/10.1016/j.ridd.2011.06.008

Wigham, S., Taylor, J. L., \& Hatton, C. (2014). A prospective study of the relationship between adverse life events and trauma in adults with mild to moderate intellectual disabilities. Journal of Intellectual Disability Research, 58(12), 1131-1140. https://doi.org/10.1111/jir.12107

World Health Organisation. (2013). Guidelines for the Management of Conditions Specifically Related to Stress. Assessment and Management of Conditions Specifically Related to Stress: mhGAP Intervention Guide Module (version 1.0). Retrieved from 
http://www.ncbi.nlm.nih.gov/pubmed/24649518 